This publication is supplemented by ODP Technical Notes 1,2 , and 3

TN1: http://iodp.tamu.edu/publications/TN/TN1-SS-Pt1-Atlas-inter.pdf

TN2: http://iodp.tamu.edu/publications/TN/TNote_2.pdf

TN3: http://iodp.tamu.edu/publications/TN/TNote_3.pdf

\title{
HANDBOOK FOR SHIPBOARD SEDIMENTOLOGISTS
}

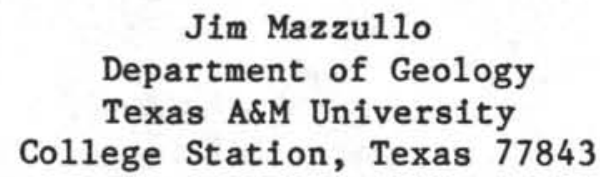

Jim Mazzullo

Department of Geology

College Station, Texas 77843
Anne Gilbert Graham Ocean Drilling Program

Texas A\&M University

College Station, Texas 77843

Ocean Drilling Program

Texas A\&M University

Technical Note No. 8

First printing 1988
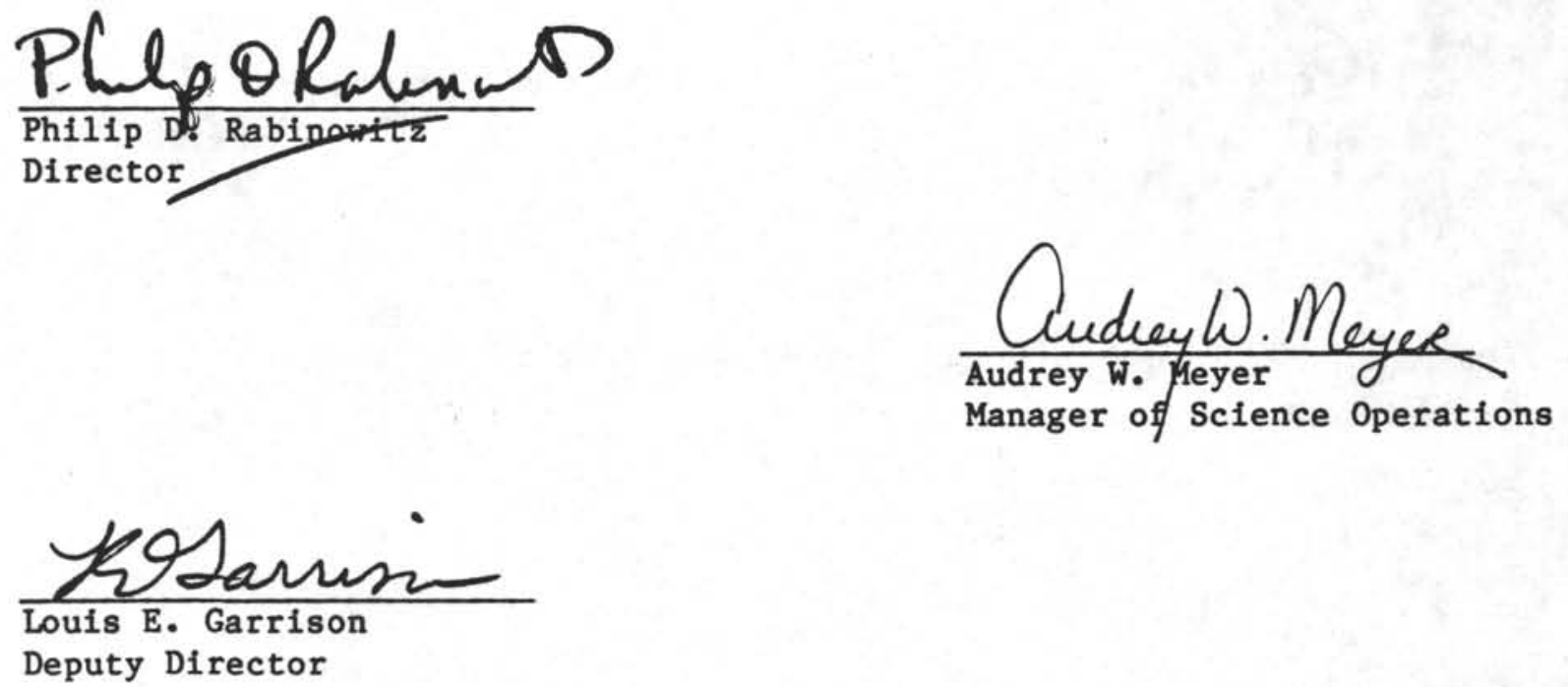
Material in this publication may be copied without restraint for library, abstract service, educational or personal research purposes; however, republication of any portion requires the written consent of the Director, Ocean Drilling Program, Texas A\&M University Research Park, 1000 Discovery Drive, College Station, Texas 77840 , as well as appropriate acknowledgment of this source.

Technical Note 8

First Printing 1988

Distribution

Copies of this publication may be obtained from the Director, Ocean Drilling Program, Texas A\&M University Research Park, 1000 Discovery Drive, College Station, Texas 77840. In some cases, orders for copies may require a payment for postage and handling.

$$
\underline{D} \underline{I} \underline{\mathrm{S}} \underline{\mathrm{C}} \underline{\mathrm{L}} \underline{\mathrm{A}} \underline{\mathrm{I}} \underline{\mathrm{M}} \underline{\mathrm{E}} \underline{\mathrm{R}}
$$

This publication was prepared by the Ocean Drilling Program, Texas A\&M University, as an account of work performed under the international Ocean Drilling Program which is managed by Joint Oceanographic Institutions, Inc., under contract with the National Science Foundation. Funding for the program is provided by the following agencies:

Department of Energy, Mines and Resources (Canada)

Deutsche Forschungsgemeinschaft (Federal Republic of Germany)

Institut Francais de Recherche pour 1'Exploitation de la Mer (France)

Ocean Research Institute of the University of Tokyo (Japan)

National Science Foundation (United States)

Natural Environment Research Council (United Kingdom)

European Science Foundation Consortium for the Ocean Drilling Program

(Belgium, Denmark, Finland, Iceland, Italy, Greece, the Netherlands, Norway, Spain, Sweden, Switzerland, and Turkey)

Any opinions, findings and conclusions or recommendations expressed in this publication are those of the author(s) and do not necessarily reflect the views of the National Science Foundation, the participating agencies, Joint Oceanographic Institutions, Inc., Texas A\&M University, or Texas A\&M Research Foundation. 
HANDBOOK FOR SHIPBOARD SEDIMENTOLOGISTS

TABLE OF CONTENTS

INTRODUCTION. .1

CHAPTER 1. GENERAL CORE HANDLING AND RESPONSIBILITIES OF SHIPBOARD

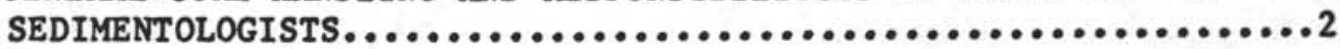

1. SEDIMENTOLOGISTS' DUTIES

2. CORE HANDLING

A. CORE DECK ROUTINE

B. CORE LAB PROCEDURES

CHAPTER 2. VISUAL DESCRIPTIONS OF CORES: METHODS AND TERMINOLOGY.......11

1. BED THICKNESS AND ATTITUDE

2. SEDIMENTARY STRUCTURES AND BEDDING PLANES

A. INTERNAL SEDIMENTARY STRUCTURES

B. BEDDING PLANES

3. BED COLOR AND LITHOLOGY

4. DRILLING DISTURBANCE

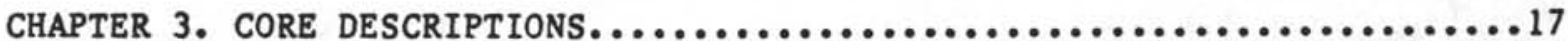

1. VISUAL CORE DESCRIPTION

2. SMEAR SLIDE/THIN SECTION DESCRIPTION

3. BARREL SHEETS

4. LITHOSTRATIGRAPHIC SECTIONS OF THE HOLE SUMMARIES

CHAPTER 4. PROCEDURES AND ANALYTICAL EQUIPMENT $\ldots \ldots \ldots \ldots \ldots \ldots \ldots \ldots \ldots \ldots \ldots$

1. PETROGRAPHIC METHODS OF ANALYSIS
A. EQUIPMENT
B. PETROGRAPHIC MEDIA
C. PETROGRAPHIC METHODS

2. GRAIN-SIZE ANALYSIS BY PARTICLE-SIZE ANALYZER

3. GEOCHEMICAL AND X-RAY-DIFFRACTION ANALYSIS

4. SAMPLING METHODS AND ANALYTICAL PROCEDURES

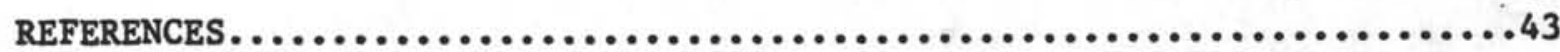

APPENDIX I. ODP SEDIMENT CLASSIFICATION SCHEME..................44 APPENDIX II. LIST OF REFERENCES PERTINENT TO THE STUDY OF SEDIMENTARY

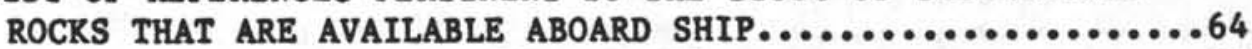

APPENDIX III. BIBLIOGRAPHY OF ODP TECHNICAL NOTES $\ldots \ldots \ldots \ldots \ldots \ldots \ldots \ldots \ldots \ldots 7$ 


\section{LIST OF FIGURES}

Figure 1. Core being carried to the catwalk from the rig floor.

Figure 2. Diagram of the lab stack's bridge deck, containing core entry, core splitting, sedimentology, physical properties, and paleomagnetics laboratories.

Figure 3. Core entry laboratory core rack (see Fig. 2 for location).

Figure 4. Core splitting room (see Fig. 2 for location).

Figure 5. Description table in the sedimentology laboratory (see Fig. 2 for location).

Figure 6. Core photograph of core sections with voids blocked by spacers (Core 117-723A-25X).

Figure 7. Blank Visual Core Description form.

Figure 8. Sedimentary structure and deformation symbol codes.

Figure 9. Hard-rock pieces separated by spacers (Core 115-706C-5R).

Figure 10. Two examples of completed Visual Core Description forms.

a. Section containing soft sediment.

b. Section containing hard sedimentary rock.

Figure 11. Blank Smear Slide/Thin Section Description form.

Figure 12. Blank Barrel Sheet.

Figure 13. Standard 1ithologic codes and symbols used in "Graphic Lithology" column on barrel sheets (see Fig. 12).

Figure 14. Example of a completed barrel sheet.

Figure 15. Three examples of illustrations from "Lithostratigraphy" sections of Hole Summaries.

a. Figure showing cored intervals, recovery, lithology, and lithologic units from Site 749 (Leg 120).

b. Figure showing sedimentary structures in recovered cores.

c. Figure showing grain size data from Hole 754A (Leg 121).

Figure 16. Comparison chart for visual percentage estimation (after Terry and Chilingarian, 1955).

Figure 17. Example of the Glagolev-Chayes point-count method. 


\section{INTRODUCTION}

The shipboard sedimentologists are responsible for describing the lithology and stratigraphy of sediments and sedimentary rocks that are recovered by the Ocean Drilling Program (ODP). They provide the first complete descriptions of the cores, which are used by shipboard and shore-based scientists as the basis for further sampling and study and for forming the first general conclusions about the geologic history of the drilling site. The shipboard sedimentologists have a tremendous responsibility to the scientific community at large, for they are commonly the only scientists who have the opportunity to see all cores from each drilling site. Thus, it is extremely important that they describe the lithology and stratigraphy of sediments and sedimentary rocks in a manner that is both complete and consistent from leg to leg.

ODP, in consultation with scientists who have been involved with the Deep Sea Drilling Project (DSDP) and ODP in the past, has attempted to define the types of data most useful to the scientific community and the procedures that should be used routinely to describe sediments and sedimentary rocks recovered by ODP. The results of this attempt are summarized in this Handbook for Shipboard Sedimentologists.

This handbook is divided into four chapters plus appendixes. Chapter 1 discusses the routine of core handling and study for all shipboard scientists in general, and outlines the basic responsibilities of the shipboard sedimentologists in particular. Chapter 2 describes the general methods and terminology for the description of the lithostratigraphy of sediments and sedimentary rocks. Chapter 3 covers procedures for the graphic and written summary of the core descriptions. Chapter 4 details the lithologic analysis of sediment, including sampling procedures, the types of analytical equipment available aboard JOIDES Resolution, and the formats for summary and presentation of lithologic data.

The handbook is appended with a description of the classification scheme used by shipboard sedimentologists to describe recovered sediments and sedimentary rocks. This classification scheme was approved by the JOIDES Planning Committee in November 1987 and implemented by the Ocean Drilling Program beginning on Leg 119 (December 1987). The second appendix contains references available aboard ship which are pertinent to the study of sediments and sedimentary rocks. The third appendix lists ODP technical notes which are also available aboard ship. 


\author{
CHAPTER 1 \\ GENERAL CORE HANDLING AND \\ RESPONSIBILITIES OF SHIPBOARD SEDIMENTOLOGISTS
}

\title{
SEDIMENTOLOGISTS' DUTIES
}

The primary responsibility of shipboard sedimentologists is to describe the lithology and stratigraphy of sediments and sedimentary rocks in cores and to provide a written interpretation about the geologic history of the drilling site. The shipboard sedimentologists also pursue their own scientific interests and assist with other scientific and curatorial duties, but their first obligation is to describe and interpret cores.

Organizing the responsibilities of the shipboard party is the job of the Co-Chief Scientists. At the beginning of the cruise, either at the pre-cruise port call or during the transit to the first site, the Co-Chiefs hold a meeting to set up specific responsibilities and schedules so that the work load is evenly divided among all shipboard scientists. Some Co-Chief Scientists divide the sedimentologists into two teams to work on opposite twelve-hour shifts, and a "chief sedimentologist" is designated for each site or hole. The Co-Chief Scientists may also specify working groups or individuals to write the "Lithostratigraphy" chapters for the Hole Summaries and to produce the barrel sheets. In addition, all shipboard scientists share the work of sampling for shipboard and shore-based requestors; this means a set schedule for each scientist of some number of hours per day at the sampling table, in addition to other obligations.

The transit to the first site is the best time to become familiar with the ship and its routines. The marine technicians and staff scientist hold mini-classes to familiarize scientists with such subjects as core handling procedures in the core $1 \mathrm{ab}$, core sampling procedures, and word-processing and graphics capabilities of the computer system. Working-group meetings may be held to coordinate shipboard duties. The staff scientist will also explain terms, forms, procedures, and routines beyond the scope of this handbook.

CORE DECK ROUTINE

\section{CORE HANDLING}

After a core is cut and brought from beneath the seafloor to the drilling platform, it is removed with its protective core liner from the outer core barrel and carried to the catwalk outside the core laboratory (Fig. 1). The 9.5-m core liner containing the cored material is set on brackets attached to the catwalk railing, the exterior is wiped clean, and the liner is marked and cut into $1.5-\mathrm{m}$ sections starting from the top of the recovered material. The last section may be shorter than $1.5 \mathrm{~m}$, depending on the total length of recovered core. Each section of the core is capped with blue endcaps at the top and clear endcaps at the bottom of each section, using acetone to seal the caps to the liner. Material in the core catcher of the outer core barrel is placed in a short section of core liner, similarly capped, and placed below the last core section. A small portion of material recovered in the core catcher is removed and taken immediately to the paleontology lab for age-dating.

Whole-round samples of a core section or sections may be removed for organic geochemistry, interstitial water, or physical properties studies. Yellow endcaps are put on these sections to indicate where a whole-round sample has been removed (usually at the bottom of a section). The core 


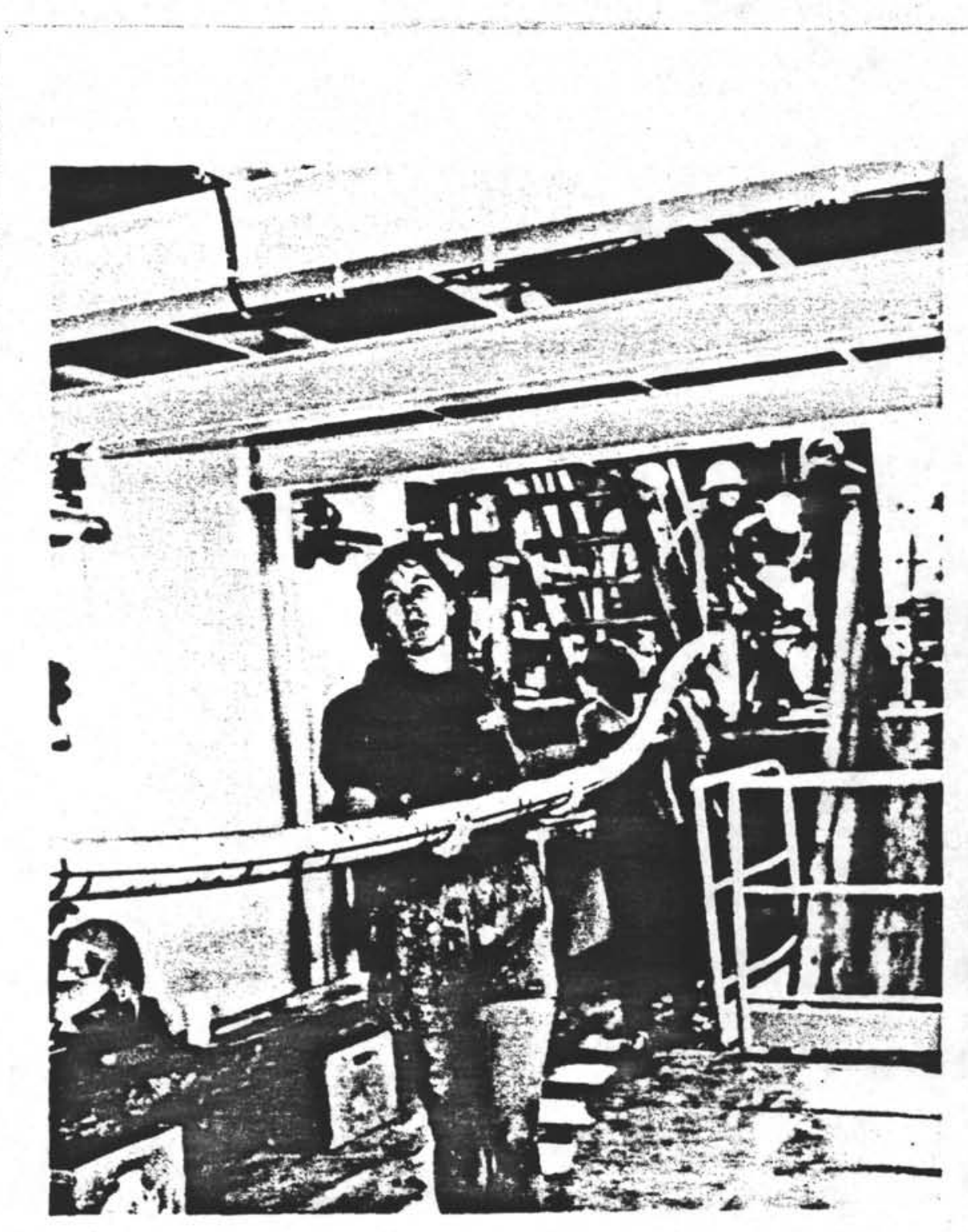

Figure 1. Core being carried to the catwalk from the rig floor. 
sections are then carried into the core laboratory (Fig. 2) and placed on a storage rack (Fig. 3). Each section is permanently labeled with its identification number: leg number, site number, hole letter, core number and type ("H" = advanced hydraulic piston core, "X" = extended core barrel, " $R "$ " rotary core barrel, etc.), and section number. For example, the second section of the tenth (rotary-drilled) core from Hole $723 \mathrm{~A}$ is labeled "117-723A-10R-2"; the core catcher section from that core is labeled "117-723A-10R, CC."

\section{CORE LAB PROCEDURES}

Information about each core is written on the core entry lab's data "white board" (Item 1 in Fig. 2) by the operations superintendent or coring technician and logged into the computer database by the marine technicians. After a core is permanently labeled and its data entered, it can be accessed for study, first by the shipboard scientists who require wholeround core sections, rather than split core sections, for their analyses. The first analyses conducted on the core sections usually include physical properties measurements (e.g., bulk density [GRAPE], sonic, and thermal conductivity), and paleomagnetics measurements (e.g., magnetic susceptibility), as well as other measurements that may be required to fulfill the scientific objectives of the leg. In the case of thermal conductivity measurements, the core sections must equilibrate to room temperature, causing a delay in processing of about 4 hours.

After the completion of whole-core analyses, the core sections are carried into the core splitting room (Figs. 2 and 4 ), where they are halved lengthwise with rotary saws or wire "cheese-cutters" by the marine technicians. One half of the split core (called the "working half") is taken to the sampling table, where the curatorial representative oversees the collection of samples for shipboard and shore-based scientists. The other half of the split core (called the "archive half") is usually run through the cryogenic magnetometer for paleomagnetic measurements and then taken to the sedimentology laboratory.

The description table in the sedimentology $1 \mathrm{ab}$ is $4.5 \mathrm{~m}$ long and $1.4 \mathrm{~m}$ wide, and can hold the archive halves of two complete cores (Figs. 2 and 5). The table is equipped with three sets of flat core racks, meter sticks, and overhead track lights. The core sections are oriented with their blue-capped tops toward the stern of the ship, with the first core section on the starboard side of the table.

The description work of the shipboard sedimentologists begins as soon as the archive half of a core (all sections) is placed on the description table. It is important to check first that the half-caps of each core section are securely fastened and that the tops of each section are properly labeled with identification numbers. The marine technicians who split the core sections will take care of endcap or labeling problems. In addition, the shipboard sedimentologists should check to see that voids in the core sections have been blocked with spacers so that the sediment or sedimentary rock cannot move along 1 ts core liner (Fig. 6). If there are open voids in the core section, the curatorial representative or marine technicians will block off the voided intervals and ensure that the archive core halves correspond exactly to the working core halves. 
SEDIMENTOLOGY LAB

2. RIG FLOOR MONITORS

. CAPSTAN MOTOR \& CORE SPLITTER

4. MICROSCOPE STATION

5. OVEN OVER HOOD

B. CLOSE-UP PHOTO TABLE

7. MINI-CORERS

8. FELKER SAW

9. TRIM SAW

10. HEAT SEALER
PHYSICAL PROPERTIES LAB

13. G.R.A.P.E. \& P.WAVE LOGGE

14. THERMAL CONDUCTIVITY

16. FAXITRON (X-RAY)

17. VANE SHEAR

18. VELOCIMETERS

19. BALANCE

20. PENTAPYCNOMETER
PALEOMAGNETICS LAB

PAL. CRYOGENIC MAGNETOMETER

DEMAL DEMAGNETIZER

24. AIC DEMAGNETIZER

25. ELECTRONICS RACK

26. MAGNETIC SUSCEPTIBILITY

PASS. THROUGH

11. COMPUTER TERMINAL

12. SAFETY SHOWER \& EYE BATH

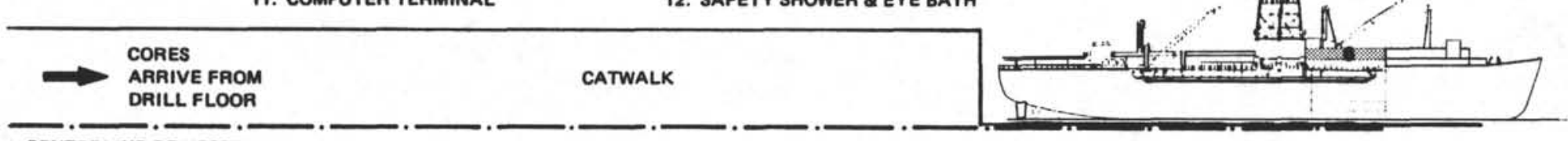

CENTERLINE OF VESSEL

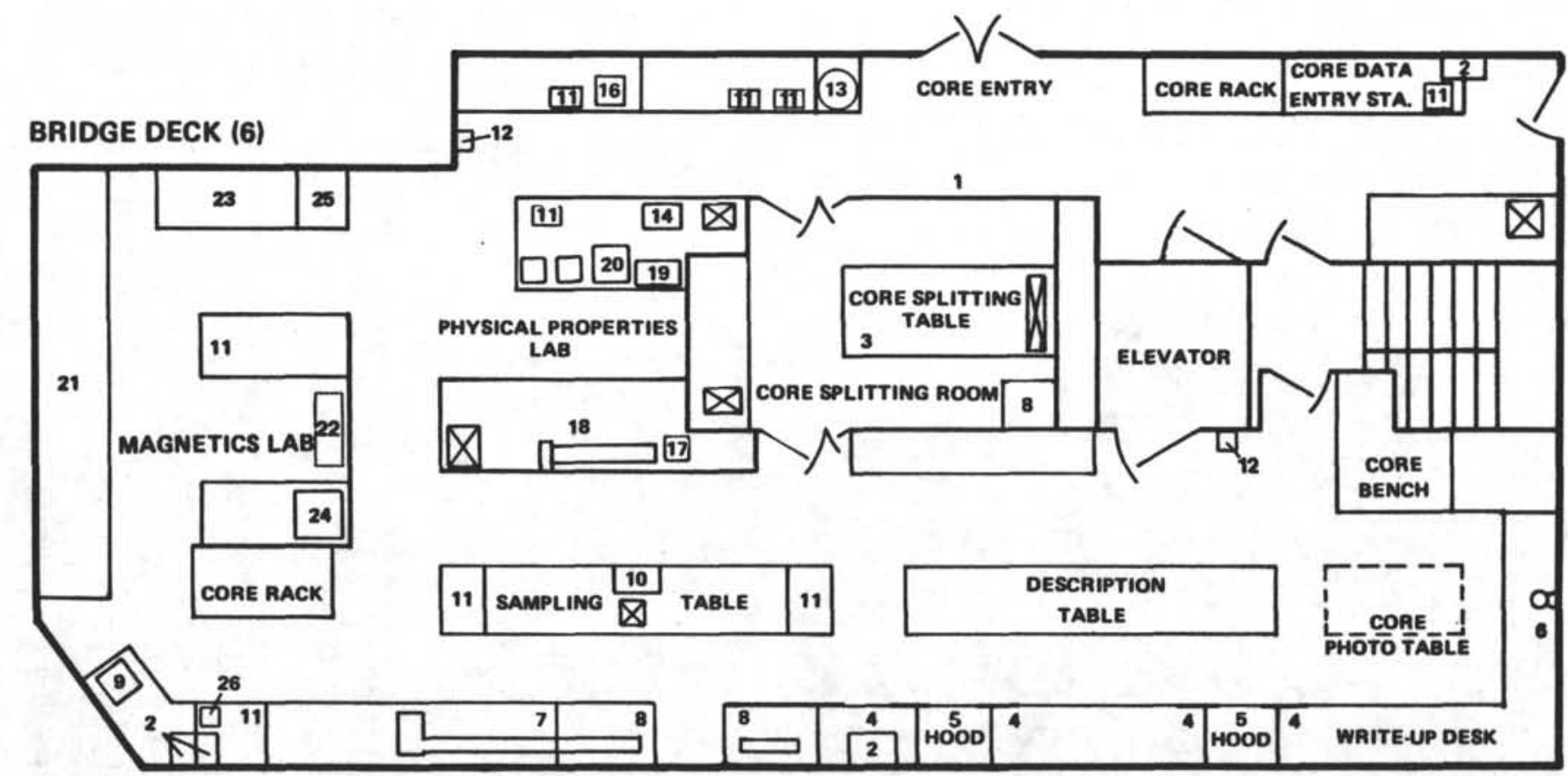

Figure 2. Diagram of the lab stack's bridge deck, containing core entry, core splitting, sedimentology, physical properties, and paleomagnetics laboratories. 


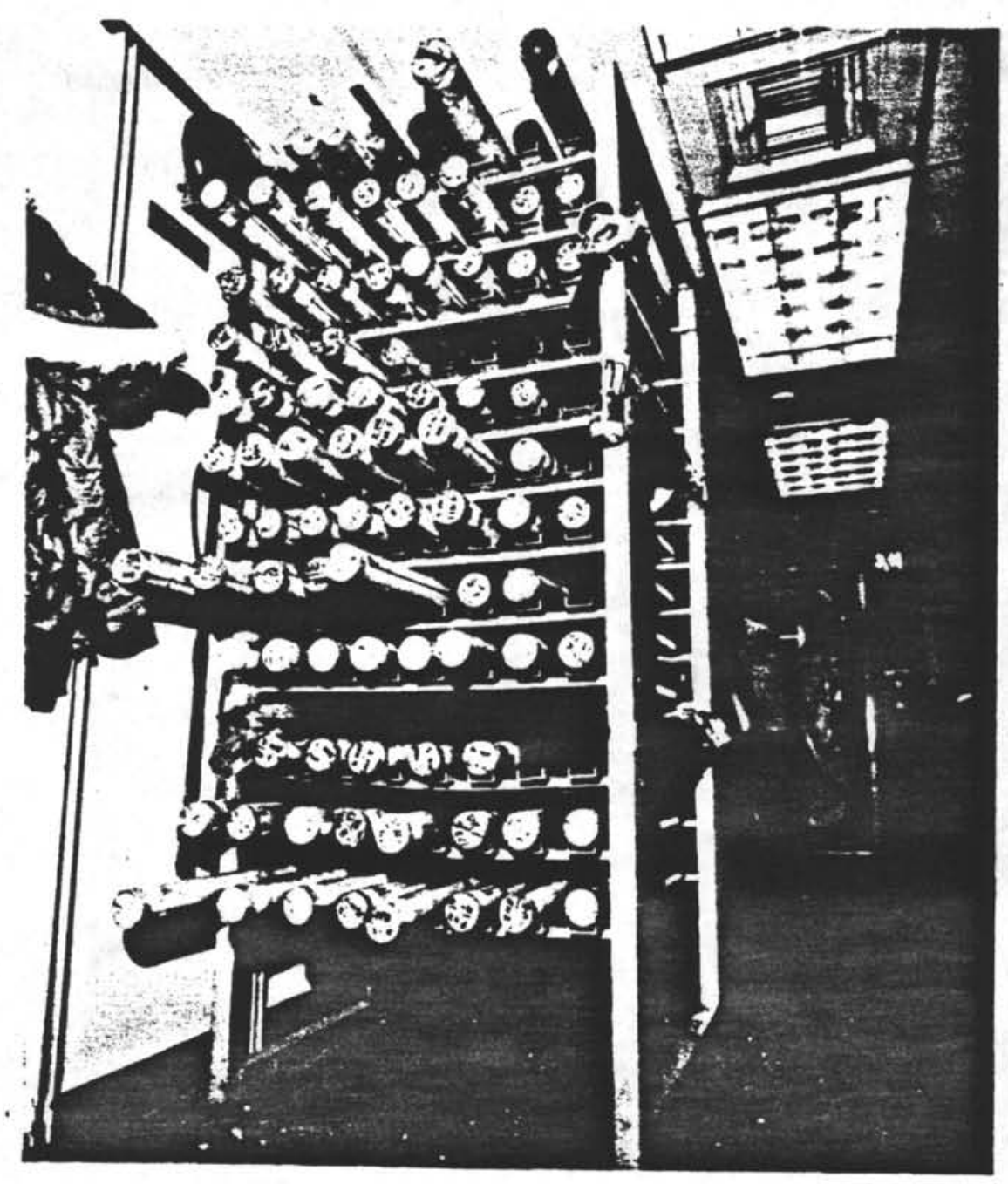

Figure 3. Core entry laboratory core rack (see Fig. 2 for location). 


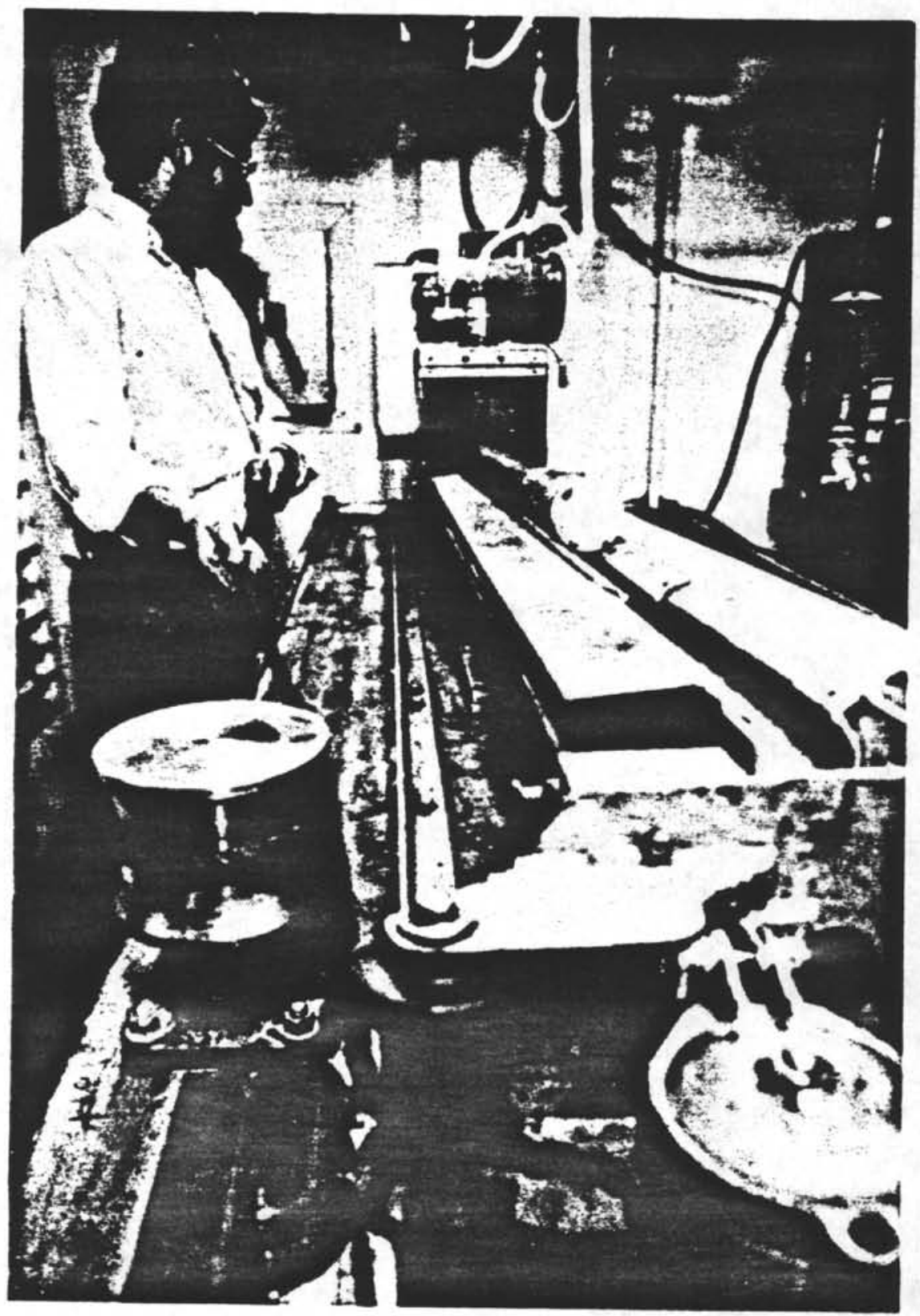

Figure 4. Core splitting room (see Fig. 2 for location). 


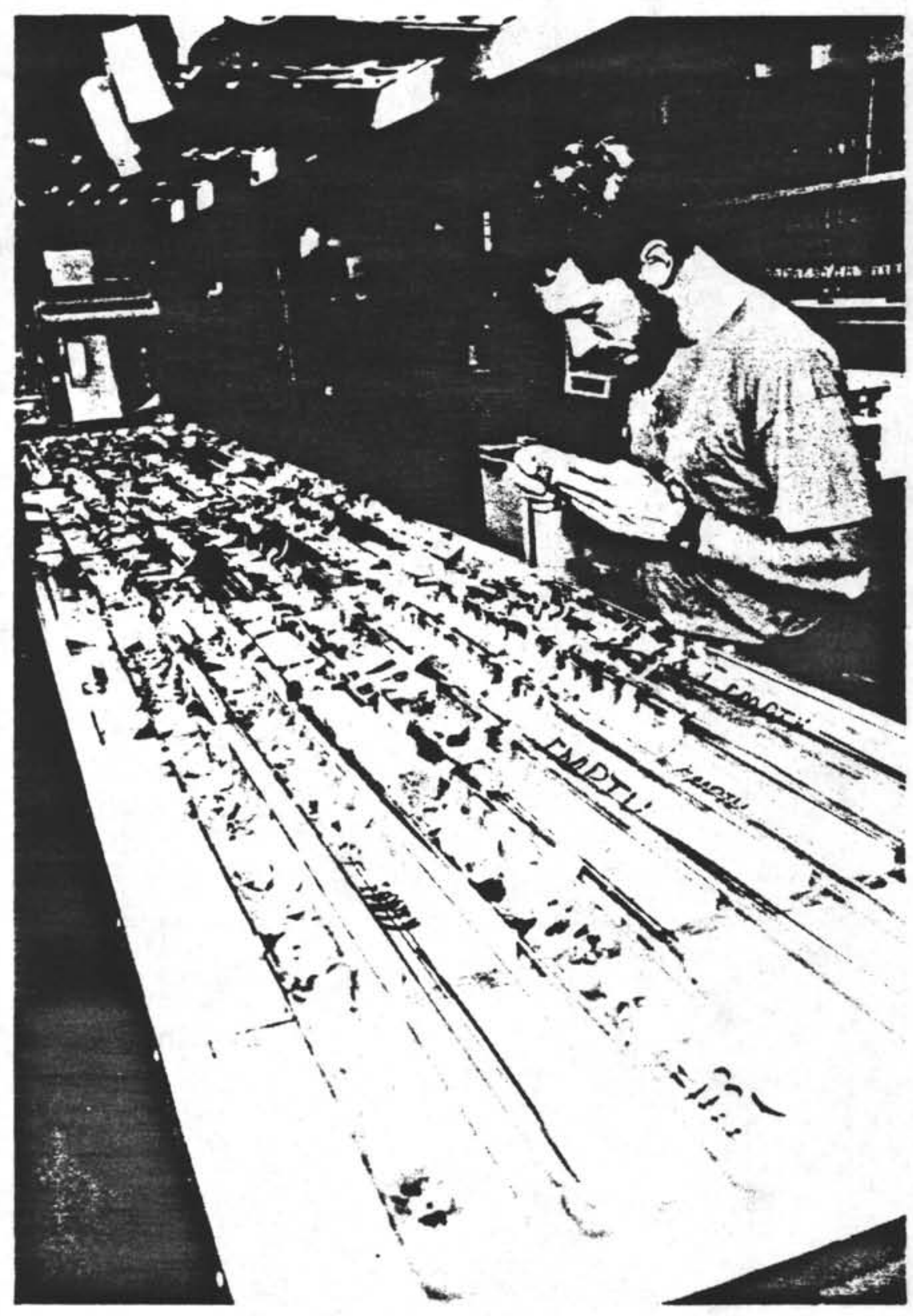

Figure 5. Description table in the sedimentology laboratory (see Fig. 2 for location). 


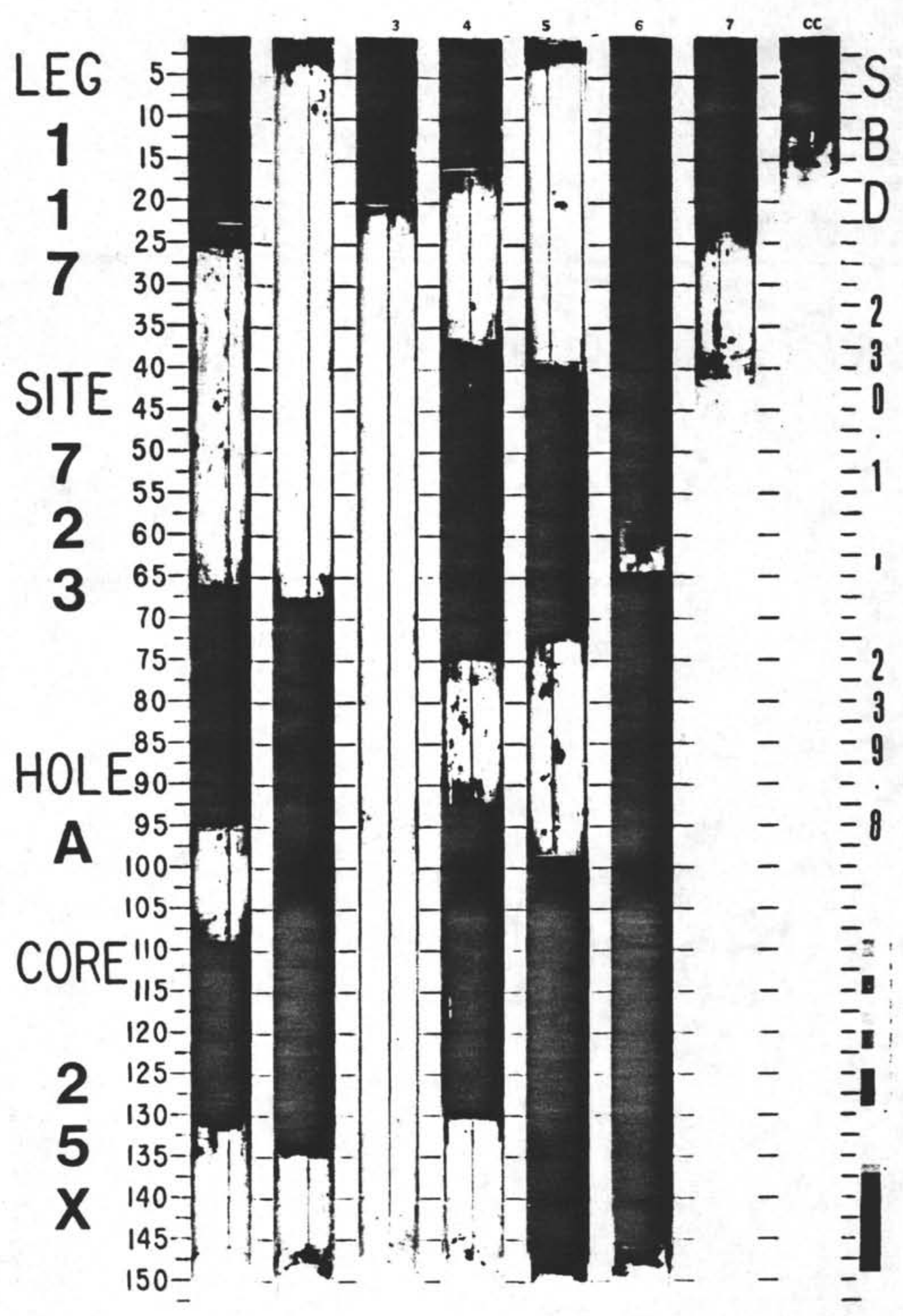

Figure 6. Core photograph of core sections with volds blocked by spacers (Core 117-723A-25X). 


\title{
CHAPTER 2 \\ VISUAL DESCRIPTIONS OF CORES \\ METHODS AND TERMINOLOGY
}

\begin{abstract}
A principal task of the shipboard sedimentologists is the bed-by-bed description of the sediments or sedimentary rocks within the cores; this description is recorded on the Visual Core Description form (Fig. 7). In the routine description of a section, the sedimentologist first defines bedding on the basis of variations in sediment lithology, color, sedimentary structures, or other pertinent characteristics, and then proceeds to describe the four major characteristics of each bed: (1) its thickness and attitude, (2) its sedimentary structures and bedding planes, ( 3 ) its lithology and color, and (4) its degree of disturbance by the drilling process. Series of beds that together constitute a fining-upward or coarsening-upward sequence should be identified also.

The purpose of this chapter is to describe the methods and terminology for detailed core description.
\end{abstract}

BED THICKNESS AND ATTITUDE

The thickness of a bed is measured with a centimeter scale. A single bed can vary from one centimeter to tens of meters, and can be characterized by the terms very thick bedded $(>100 \mathrm{~cm}$ thick), thick bedded (30-100 cm thick), medium bedded (10-30 cm thick), thin bedded $(3-10 \mathrm{~cm}$ thick), and very thin bedded (1-3 cm thick) (McKee and Weir, 1953).

The attitude of a bed within a core may be horizontal or inclined, and may be the product of natural sedimentary or tectonic conditions or of drilling disturbance. The attitude of a bed should be noted if it is not horizontal, and should be measured with a protractor if the inclination is apparently natural (that is, not the product of drilling disturbance).

SEDIMENTARY STRUCTURES AND BEDDING PLANES

Sediments and sedimentary rocks can contain one or more types of sedimentary structures. The sedimentary structures can be mechanical in origin (formed during or shortly after the deposition of the sediment), organic in origin (formed by the reworking of sediment by biota), or chemical in origin (formed by inorganic chemical processes after deposition). Complete descriptions and illustrated examples of sedimentary structures are available in a number of references in the shipboard library (Appendix II lists library holdings relating to sedimentologic description); some of the structures more commonly observed in ODP cores are also described below.

Internal Sedimentary Structures

The internal (cross-sectional) sedimentary structures that are exposed on the surface of a core can be described using the following terms (symbols for these structures are shown in Fig. 8):

1. Nornal graded describes a bed that exhibits a gradual upward decrease in grain size.

2. Reverse graded describes a bed that exhibits a gradual upward increase in grain size.

3. Laninated describes a bed that contains thin $(<1 \mathrm{~cm})$ horizontal or inclined beds (laminae) with no internal foresets. The thickness of the individual laminae can be described by the following terms:

a. thickly laminated: the laminae are $>0.3 \mathrm{~cm}$ thick; and

b. thinly laminated: the laminae are $<0.3 \mathrm{~cm}$ thick. 


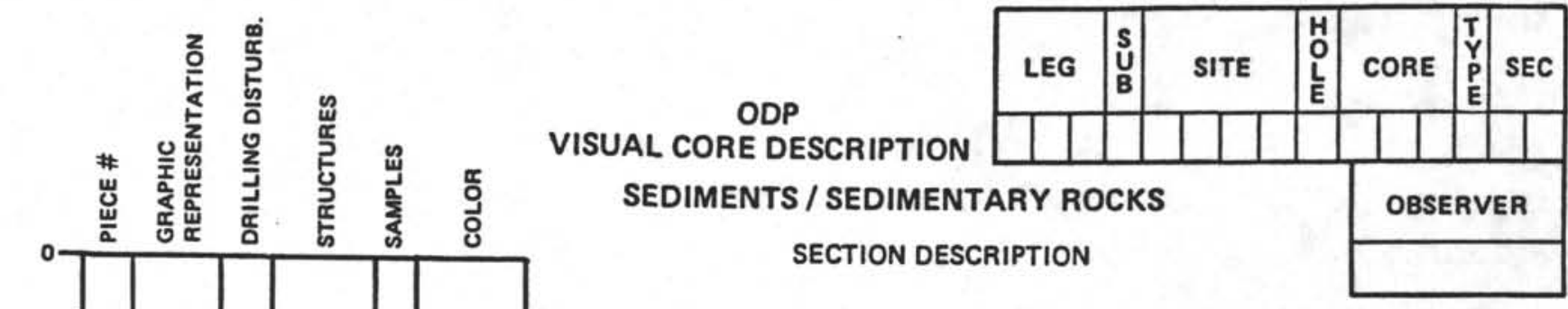

00 These data are to be processed into a computerized data base along with existing standardized data from other legs and will be accessible to the scientific community at large. RECORD ALL MEASUREMENTS CAREFULLY, COMPLETELY, AND LEGIBLY.

Figure 7. Blank Visual Core Description form. 
SEDIMENTARY STRUCTURE SYMBOLS

DRILLING DEFORMATION SYMBOLS

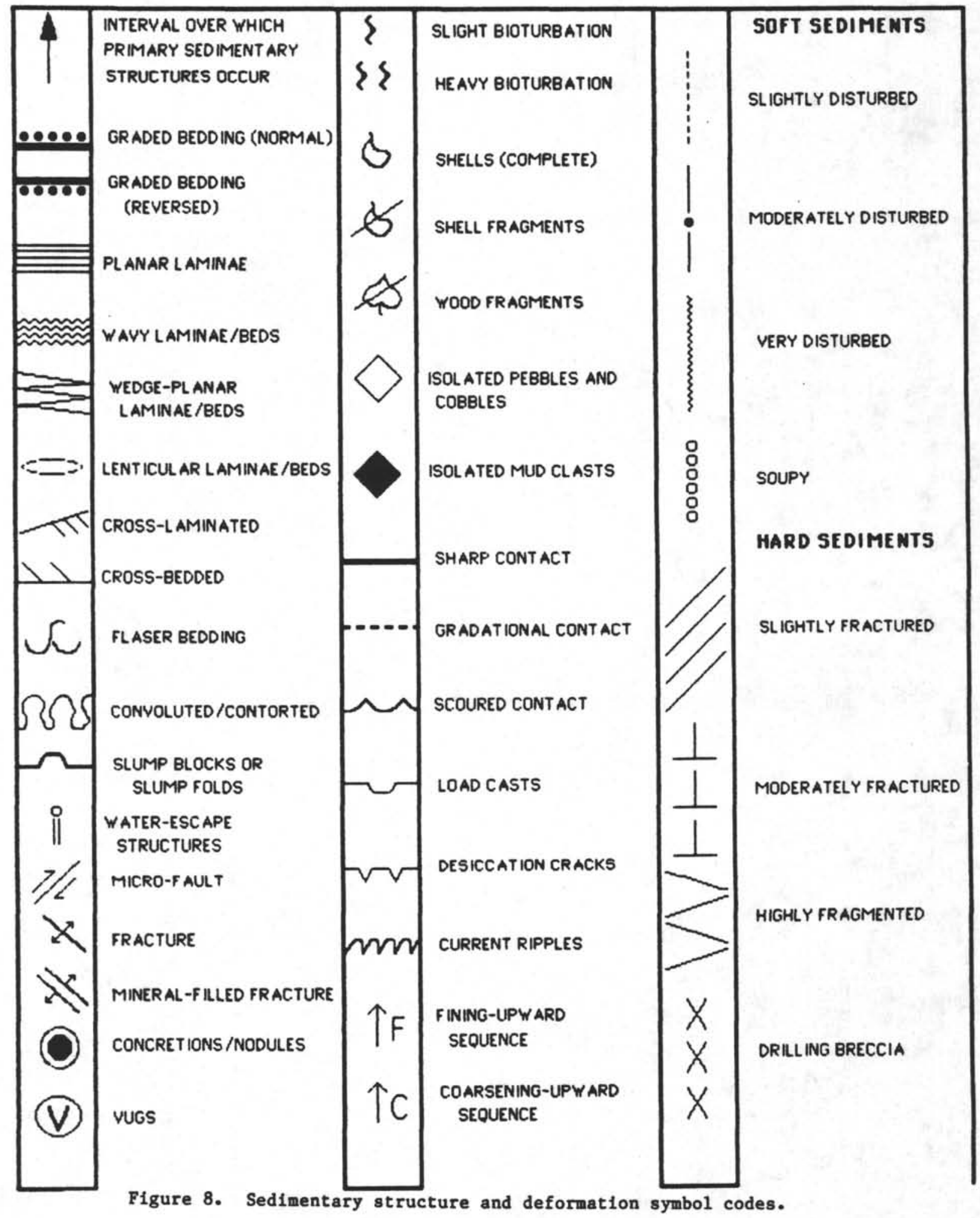


The geometry of individual laminae can be described by the following terms: a. planar laminated: the laminae are bounded by parallel and planar bedding planes, and are continuous in thickness across the width of the core;

b. wavy laminated: the laminae are bounded by one or two wavy and parallel bedding planes, and are continuous but variable in thickness across the width of the core;

c. wedge-planar laminated: the laminae are bounded by non-parallel and planar bedding planes, and pinch out in one direction across the width of the core; and d. lenticular: the laminae are bounded by one or two wavy and non-parallel bedding planes, and pinch out in two directions across the width of the core.

Lamination of fine sediments is generally the result of slight changes in texture or composition which may be due to organic action (as in stromatolites) or to variations in current velocity and turbulence, sediment supply, or climate (as in varves or muddy turbidites). Lamination of coarser grained (sand and gravel) sediment is generally the result of upper flat-bed flow, sheet flow, or wind-ripple migration (e.g., Harms et al., 1982).

4. Cross-laninated describes a bed that contains thin horizontal or inclined laminae less than $1 \mathrm{~cm}$ in thickness with inclined internal foresets. The thickness of the individual laminae can be described as thickly or thinly laminated, and their geometry as planar, wavy, wedgeplanar, or lenticular (see above). The type of cross-laminations can be described by the following terms:

a. tabular: the foresets are planar and parallel, and intersect the lower bedding plane at an angle; and

b. trough: the foresets are curved and parallel and intersect the lower bedding plane tangentially.

Cross-lamination is generally the product of ripple migration.

5. Cross-stratified (or cross-bedded) describes a bed that contains inclined internal foresets (and possibly subhorizontal topsets and bottomsets) greater than $1 \mathrm{~cm}$ in thickness. The cross-bedding may be described as either tabular or trough cross-bedded, using the same criteria that are described for cross-laminated sediments. Cross-bedding is generally a product of dune (sand wave and megaripple) migration.

6. Flaser-bedded describes a bed that contains thin horizontal or inclined laminae with inclined internal foresets and thin (less than $1 \mathrm{~cm}$ ) lenses of another sediment type within their troughs. Flaser beds are generally the products of variations in current energy (e.g., flaser-bedded tidal sand and mud or turbidite silt-mud units); the lenses are commonly fine-grained sediment that accumulates in the troughs of ripples during low-energy periods.

7. Convoluted describes a single bed whose internal laminations have been intricately folded. The folding does not generally extend to the bedding planes or into adjacent beds. Convoluted beds or slunp folds are generally gravity-induced soft-sediment deformation structures, and are most common to sand and silt.

8. Hater-escape pipes (fluid-escape structures) are features produced by the escape of fluids from a bed after deposition, including "dish," "pillar," and "vertical sheet" structures.

9. Hicro-faulted describes a single bed whose internal lamination has been disrupted and vertically displaced by micro-faults. The faults do not 
generally extend to the bedding planes or into adjacent beds. They are gravity-induced soft-sediment deformation structures, and are common to beds that are deposited on high slopes (e.g., dune avalanche faces).

10. Fractured describes a bed that is naturally fractured or jointed along planes which extend through 1 ts bedding planes and into adjacent beds. The fracture may be empty or partly or completely filled by authigenic minerals.

11. Nodular describes a bed that contains discrete nodules of a different sediment type. Nodules are generally formed by syn- or postdepositional precipitation or recrystallization of chert, pyrite, halite, anhydrite, gypsum, phosphorites, calcite, manganese, and other minerals on the surface of or within a bed.

12. Nodular-nosaic describes a bed that contains coalesced nodules of chemical minerals. Nodular-mosaic beds are commonly formed by the syn-depositional precipitation of evaporites within a bed. The nodules grow within, and eventually displace and replace, the original sediment in the bed, and merge to form sutured contacts. Remnants of the original sediment are commonly present within and between the nodules.

13. Vuggy describes a bed with large cavities or pores ("vugs"). The vugs are generally formed by shrinkage (as in birdseye limestone), dissolution (as in moldic pores or true vugs), bioturbation (as in borings), and framework growth (as in reefs), and may be partly or completely filled by detritus or authigenic minerals.

14. Slightly bioturbated describes a bed that has been partially disturbed by bioturbation. Trace fossils from burrowing organisms are present and perhaps abundant on the exposed surface of the bed (and should be described), but the bed's primary depositional stratification is still apparent.

15. Heavily bioturbated describes a bed whose original stratification has been highly or completely disturbed by bioturbation.

16. Massive or structureless describes a bed that is homogeneous in lithology and color and exhibits no bedding, cross-bedding, grading, bioturbation, or bed disturbance. Massive beds are the products of rapid sedimentation, grain-flow deposition, or bioturbation, but show no evidence for their origins. They are also common to coarse sand and gravel deposits, as well as to supermature sediments.

17. Fossiliferous describes a bed containing one or more macrofossils. The fossil types should be identified, if possible.

18. Pebbles, cobbles, and mud clasts should be identified when they occur isolated in a section; for example, glacial dropstones and rip-up mud chips.

Bedding Planes

A description of the sedimentary structures of a bed should also include a description of the types of bedding planes and, if observable, any structures or markings upon them (surface and sole marks). A bedding plane can be described as sharp or gradational and planar or wavy; the surface and sole marks can be described by the following terms (Fig. 8):

1. Scours: sharp, wavy lower bedding planes that clearly truncate underlying beds.

2. Load marks: small knobby depressions on an upper bedding plane (with corresponding load casts on the underside of the overlying bed) that are formed by the sinking of a more dense sediment into a less dense sediment. 
3. Desiccation cracks: downward-tapering v-shaped fractures on an upper bedding plane.

4. Ripple arks: wavy upper bedding plane formed by symmetrical or asymmetrical ripple crests.

BED COLOR AND LITHOLOGY

Bed color is determined by visual comparison with the Geological Society of America Rock-Color Chart or Munsell Soil Color Charts (available aboard ship). Bed color should be described as soon as the core has been split and while the sediment is still wet, because drying and oxidation of exposed sediment can have drastic effects on its original color.

The lithology of the sediment in a bed is determined by an analysis of

its texture and composition by visual study of the core, petrographic study of smear slides and thin sections, X-ray diffraction analysis, and geochemical analysis. Given these data, the lithology of the sediment in a bed is described by a principal name that defines its sediment type and class, and major and minor modifiers that describe its texture and composition. Appendix I contains the sediment classification scheme used by ODP.

DRILLING DISTURBANCE

Three types of drilling disturbance features are common to sediments and sedimentary rocks recovered by ODP (Fig. 8):

1. Bed flexures: beds of soft sediment can be flexed and bowed downward by the weight of the drill stem, or can be flexed and bowed upward as the core barrel is pulled from the hole. This deformation can be characterized as slightly deformed (when beds are only flexed along their edges), moderately deformed (the beds are entirely flexed across the width of the core), and very deformed (when the beds are completely disturbed or exhibit diapir-like structures).

2. Soupy beds: beds of water-saturated or under-consolidated soft sediment will often flow upwards through a core barrel under the weight of the drill stem, and will thereby lose all traces of their original bedding. This is very common to sand, calcareous grainstones, and ooze, and is frequently observed in the first core which penetrates the poorly consolidated sediment on the surface of the sea bed.

3. Fractures: beds of hard sedimentary rock can be fractured by excess drill pressures. The rock can be considered slightly fractured when it is broken into a few large pieces by a small number of well-defined fractures, moderately fractured when core pleces are in place or partly discplaced but original orientation is maintained, or highly fractured when pieces are probably in correct stratigraphic sequence (although they may not represent the entire sequence) but original orientation is lost. Drilling breccia is rock crushed and broken into many small and angular pieces, with original orientation and stratigraphic position lost; often drilling breccia is completely mixed with drilling slurry. Beds of soft sediment can also be split along their bedding planes by the rotation of the core barrel during rotary coring. In this case, the fracturing produces disc-shaped drilling biscuits that commonly float within a matrix of soupy sediment. Drilling biscuits can be very common in rotary-cored sections, and can be difficult if not impossible to identify.

Drilling disturbance should be brought to the attention of the Operations Superintendent, because it can sometimes be lessened or prevented by changing drilling or coring techniques. Disturbance can be caused also by the tools used for splitting cores, and the marine technicians may be able to minimize core disturbance from this source. 


\section{CHAPTER 3 \\ CORE DESCRIPTIONS}

There are four types of graphic and written summaries of the core descriptions which must be completed by the shipboard sedimentologists before the end of the cruise: Visual Core Descriptions, Smear S1ide/Thin Section Descriptions, Barrel Sheets, and the "Lithostratigraphy" sections of the Hole Summaries.

\section{VISUAL CORE DESCRIPTION}

A Visual Core Description (VCD) form is completed for each section of each core (including the core catcher). The VCD is the most detailed summary of the stratigraphy, bed thickness, lithology, and structures of the sediments or sedimentary rocks at the drilling site, and must be completed with careful attention.

A blank VCD form for sediments and sedimentary rocks is shown in Figure 7. The VCD form consists of three no-carbon-required sheets which are destined for different parts of the data storage system. The VCD form must be filled out with a black ball-point pen (not pencil, felt-tipped pen, fountain pen, blue, red, or green ball-point pen, or other writing implement) and a firm and legible hand so that the data are recorded clearly on all three sheets. The text on the VCD must be written in English.

Title boxes in the upper right corner of the VCD form identify the core section described on that page. The title boxes are filled (before starting the section description) with the leg and site numbers, hole letter, core number and type, section number, and the initials of the observer.

The left side of the VCD form contains a series of columns that are bordered by a linear scale in centimeters. The columns are used to graphically represent different properties of the sediments or sedimentary rocks in the core section.

Piece : Number pieces of broken indurated core. When a core section contains broken rock, the sedimentologists on watch and the curatorial representative fit the pieces together along fractures, or (when a fit is not obvious) separate the pieces with spacers (Fig. 9). Each piece or refitted group of pieces is marked with a number, starting with " 1 " at the top of each section, and each piece within a refitted group is further distinguished by a letter, starting with " $\mathrm{A}$ " at the top of each refitted group (e.g., 2A, 2B, 2C).

Graphic Representation: Illustrate the arrangement and approximate size and shape of the pieces or refitted groups of pieces. Also illustrate any sedimentary features mentioned in the written description (see below).

Drilling Disturbance: Record the effects of drilling upon the internal stratification of sediments and sedimentary rocks. The graphic symbols for drilling disturbances are shown in Figure 8.

Structures: Illustrate the bedding planes, thickness, and sedimentary structures of each bed in the core section. Bedding planes are generally illustrated by solid or dashed lines (for abrupt and gradational contacts, respectively) that are planar or wavy (and inclined when the bedding is inclined); additional symbols are employed for erosive lower bedding planes and for bedding planes with distinctive surface and sole marks (Fig. 8). The types of internal sedimentary structures and their vertical sequences within a bed are also graphically represented in this column (Fig. 8). 


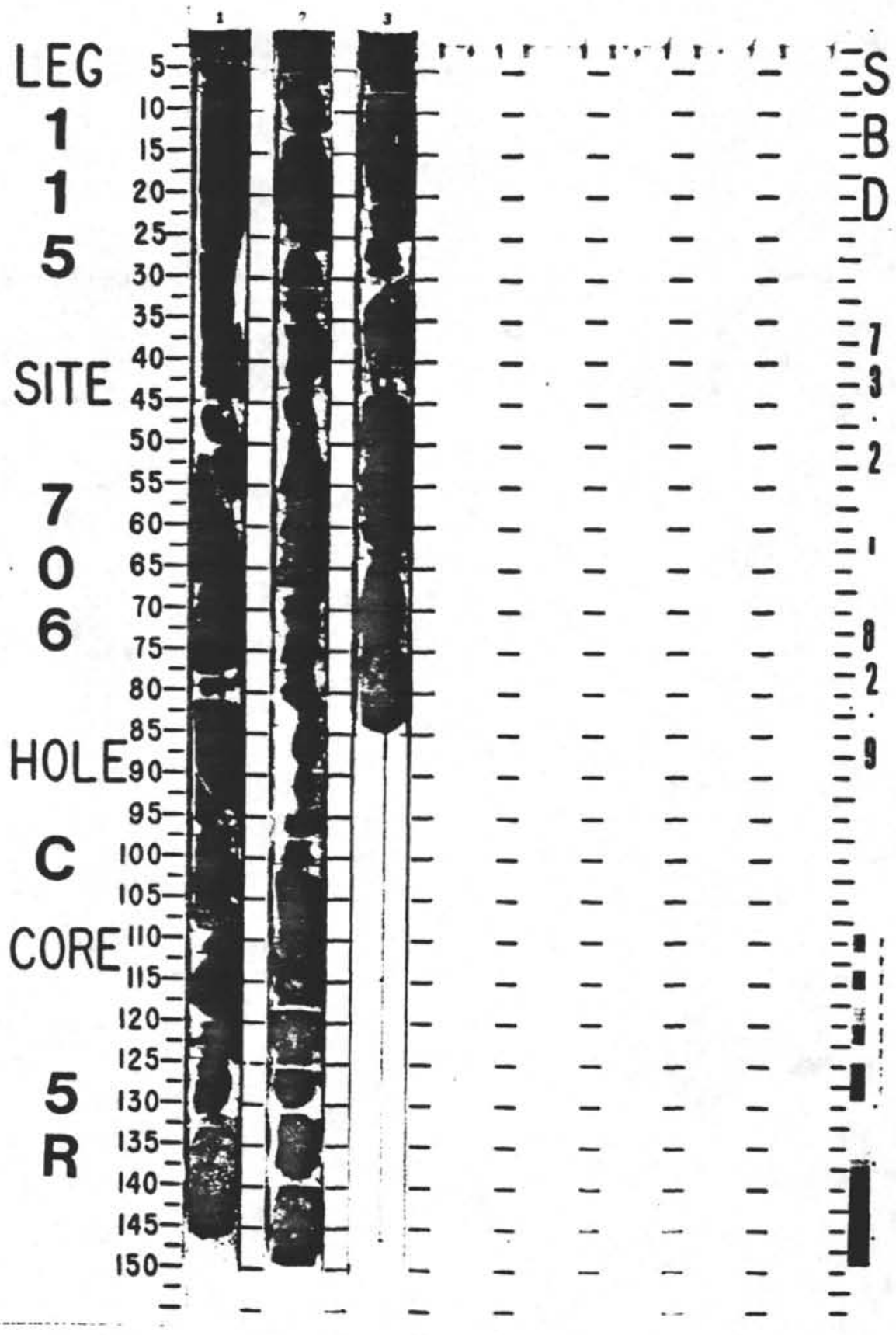

Figure 9. Hard-rock pieces separated by spacers (Core 115-706C-5R). 
Samples: Mark the locations of all samples that are collected from the working or archive halves of the section for routine shipboard analyses. Smear slide locations are marked with an asterisk (*); thin section locations are marked with a pound sign (\#). Samples collected for personal research are not noted. A record of the results of the 1ithologic analyses must be completed of all smear slides or thin sections noted in this column. (Additional smear slides can be made for rapid analysis to aid the core description; these are not noted on the Visual Core Descriptions unless formally described.) Interstitial water (IW), Organic Geochemistry (OG), and Physical Properties (PP) whole-round samples are labeled in this column and marked in the other columns with a broad $X$ across the entire missing interval.

Color: Describe the hue, value, and chroma (e.g., 10YR 8/2) of the sediment( $s$ ) in each bed in the core section. If a bed contains two or more sediment types, the color of each type should be clearly indicated. Similarly, if a bed contains two or more interlaminated sediments of different colors, the colors are shown in the column and listed to the right in decreasing abundance. If a bed grades upward from one color to another, the colors at the extreme upper and lower parts of the bed should be indicated and separated by a dashed line. A disproportionate amount of time should not be spent on color description, as it is but one aspect of the description of the sediment as a whole.

Voids within the core section are indicated by a broad " $\mathrm{X}$ " that crosses all six columns.

The right side of the Visual Core Description form contains room for a detailed written description of each bed. For each bed, the following data should be routinely reported:

1. Interval (in $\mathrm{cm}$ ) that is occupied by the bed (e.g., "10 - $45 \mathrm{~cm}$ ");

2. Lithology of the sediment(s) in the bed (written in capital letters and underlined);

3. Internal sedimentary structures;

4. Types of bedding planes (sharp, gradational, planar, or wavy) and surface and sole marks; and

5. Minor but notable features (e.g., fossils, lenses, or nodules of different sediment types).

This description can be followed by an interpretation of the genesis of the bed (e.g., "turbidite"), if desired. However, the VCD is meant to contain a description rather than an interpretation of the cores, so any interpretations or genetic descriptors such as "turbidite" or "debris flow" should be kept out of the main body of the description.

Two examples of completed VCD forms are shown in Figure 10a-b.

\section{SMEAR SLIDE/THIN SECTION DESCRIPTION}

Smear slides of unconsolidated material and thin sections of "hard rocks" are prepared aboard ship to document the lithology of recovered material and to aid in core description. Primarily, they are made from all representative lithologies, and also from special or unique layers of particular interest. Thus, the number of smear slides (or thin sections) produced is a function of the homogeneity of the sedimentary section.

Until Leg 119, the results of petrographic analysis of a sediment or sedimentary rock were reported on the ODP Sediment Smear Slide/Thin Section Description form (Fig. 11). Beginning with Leg 119, the ODP Computer 


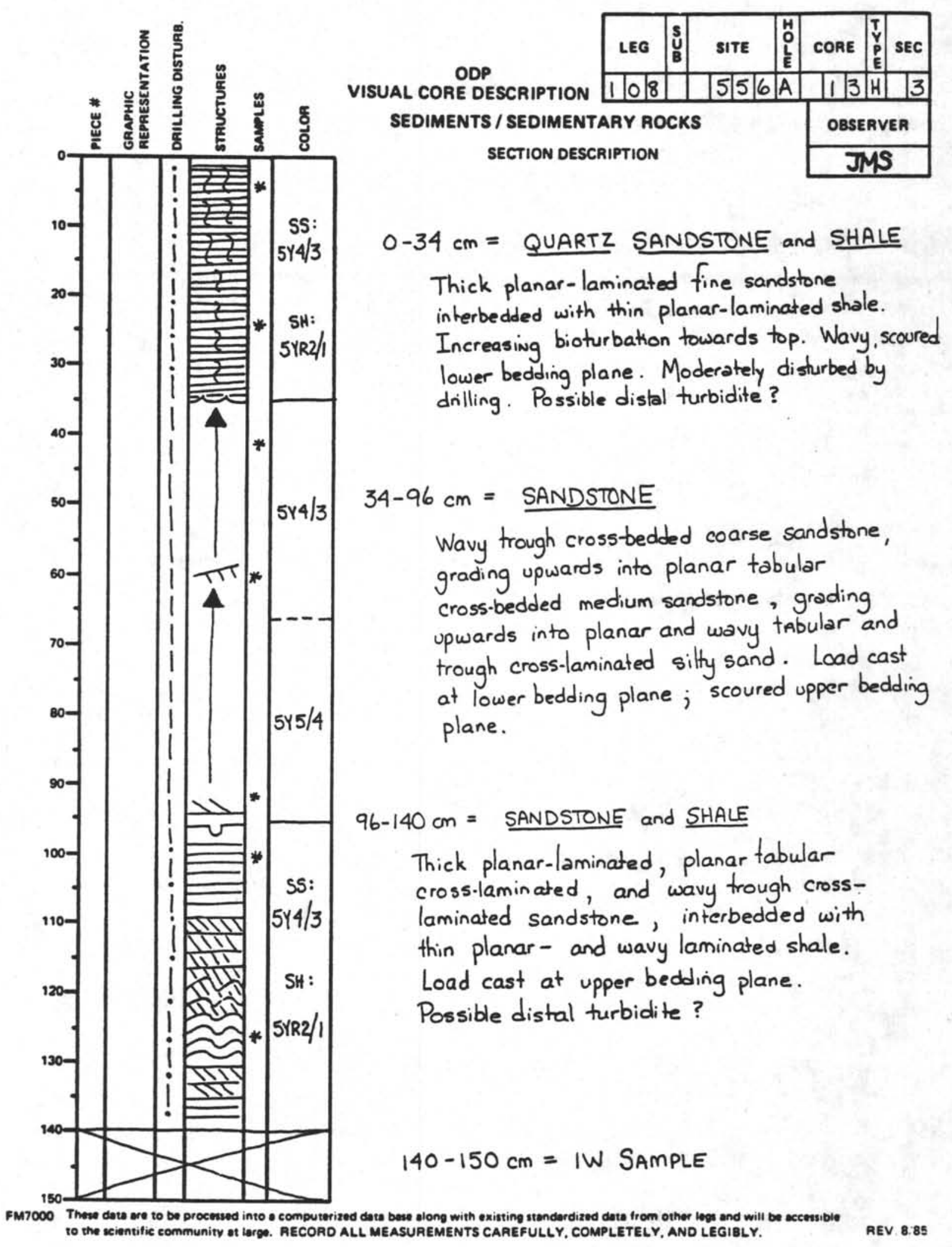

Figure 10a. Example of a completed Visual Core Description form. Section containing soft sediment. 


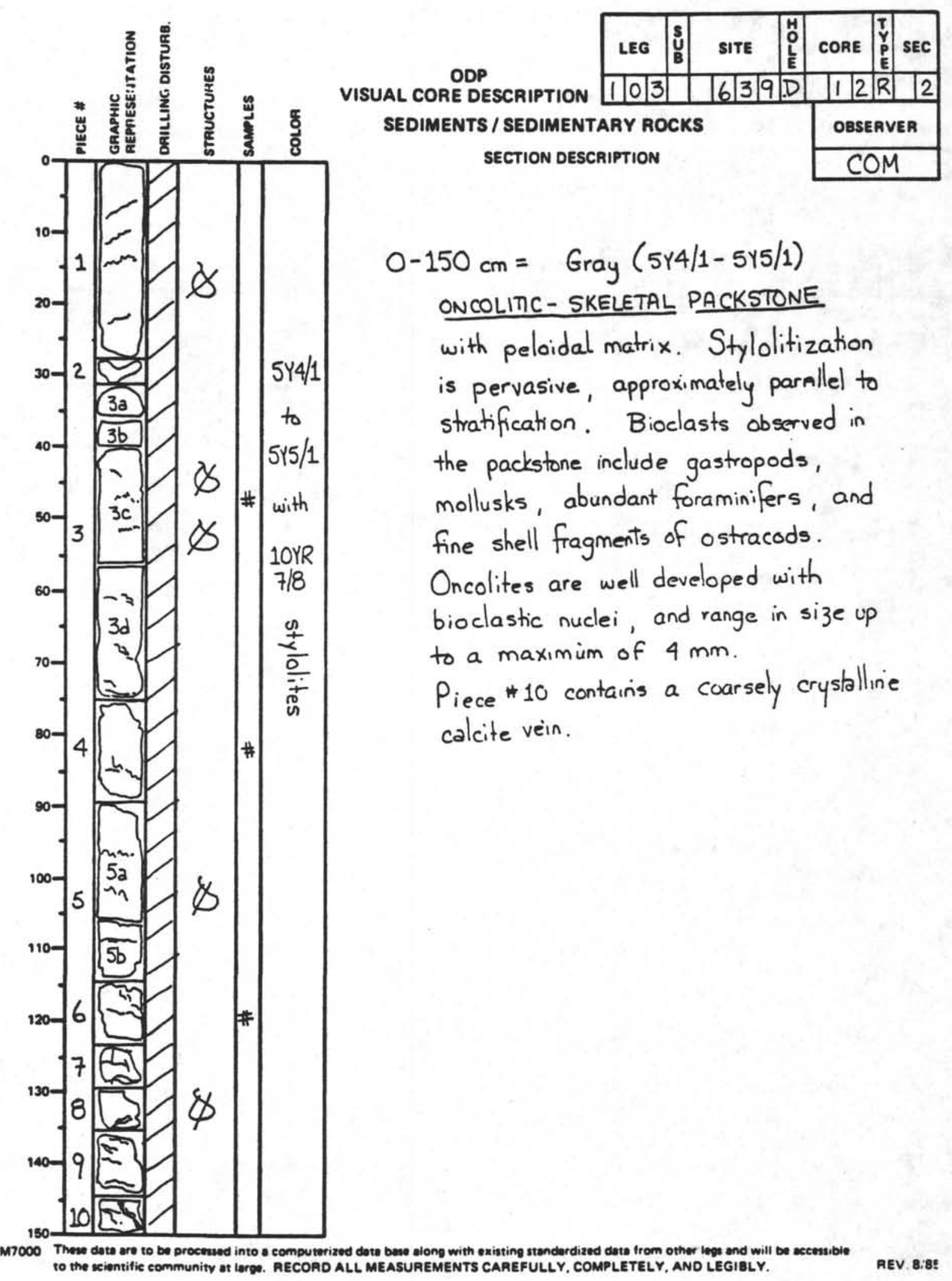

Figure 10b. Example of a completed Visual Core Description form. Section containing hard sedimentary rock. 


\section{2}

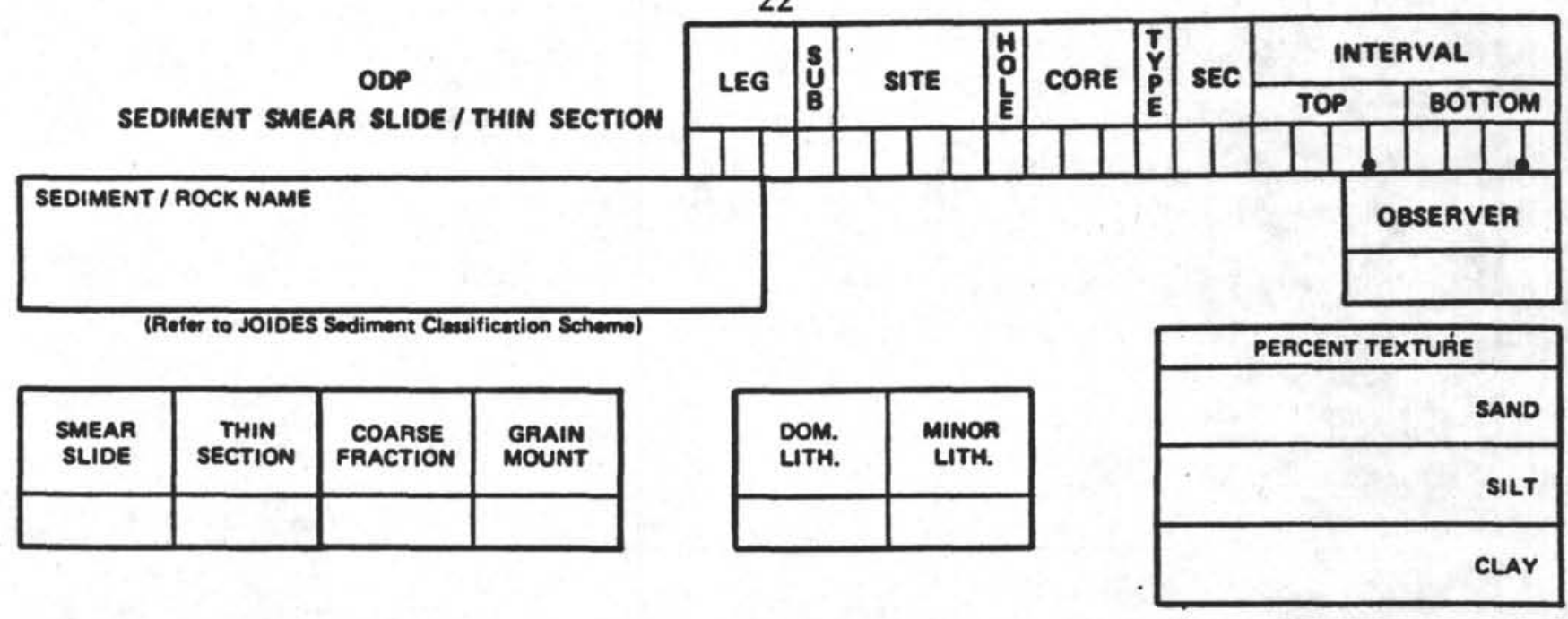

\begin{tabular}{|c|c|c|c|}
\hline PERCENT & COMPOSITION & PERCENT & COMPOSITION \\
\hline & QUARTZ & & FORAMINIFEAS \\
\hline & FELOSPAR & & NANNOFOSSILS \\
\hline & ROCK FRAGMENTS & & DIATOMS \\
\hline & MICA & & RADIOLARIANS \\
\hline & CLAY & & SPONGE SPICULES \\
\hline & VOLCANIC GLASS & & SILICOFLAGELLATES \\
\hline & INORGANIC CALCITE & & FISH REMAINS \\
\hline & DOLOMITE & & PLANT DEBRIS \\
\hline & CEMENT & & ooids \\
\hline & PORE SPACE & & PELLets \\
\hline & ACCESSORY MINERALS & & BIOCLASTS \\
\hline & & & INTAACLASTS \\
\hline & & & SPAR CEMENT \\
\hline & & & MICAITE \\
\hline & & & \\
\hline & & & \\
\hline & & & \\
\hline & & & \\
\hline & & & \\
\hline & . & & . \\
\hline & & & \\
\hline & & & \\
\hline & & & \\
\hline
\end{tabular}

REMARKS:

TOTAL MUST EOUAL $100 \%$

These data are to be processed into a computerized daw bese along with existing standardized data from other legs and will be accessible to the scientific community ot largo. RECORD ALL MEASUREMENTS CAREFULLY, COMPLETELY, AND LEGIBLY. 
Services Group installed software (called SLIDES) that allows these data to be entered directly into the shipboard computer system in a format similar to that of the paper forms.

SLIDES is a computerized data collection and reporting package designed to handle entry and updating of information from smear slides, thin sections, grain mounts, and coarse-fraction slides. SLIDES then can prepare two types of reports: a Barrel Summary to be attached directly to the core's barrel sheet (see below), and a downhole stacked line graph of the normalized abundance of five user-selected sedimentary components.

To use SLIDES, the scientist types onto a computerized screen form the slide identification information, the 10-1etter assigned component codes for the observed components, and the components' percentages. A 1ist of the component codes is kept in the sedimentology lab. SLIDES ensures the quality of the data collected by submitting it to a variety of checks. The paper Smear Slide/Thin Section Description form should be used in place of SLIDES if the SLIDES program is unavailable for any reason.

The FINDCOMP report routine allows selection of records from across the entire leg based on the appearance of an individual component, or based on a percentage level of a group of components. Users' guides have been written for SLIDES and for FINDCOMP. There is also online help within the programs, and further assistance is available aboard ship from the Computer System Manager.

Sets of representative smear slides and mineral grain mounts are available aboard ship for comparison purposes.

\section{BARREL SHEETS}

A single Barrel Sheet is completed for every core. These barrel sheets will be published in the Initial Reports volume of the Proceedings of the Ocean Drilling Program, and are the only complete sumary of the drilling site stratigraphy seen by the general scientific community.

A blank Barrel Sheet is shown in Figure 12. The top of the barrel sheet contains a series of spaces that identify the leg, site, hole, and core number and type. Additional spaces are provided for the position of the core within the hole [drill-string depth in meters below sea level (mbsl) and meters below seafloor(mbsf)]; depth information is posted by the Operations Superintendent or SEDCO coring technician on the "white board" in the core entry $1 \mathrm{ab}$, and a correction factor for the accurate distance from rig floor to sea level is available from the Operations Superintendent for each hole. This correction factor may vary slightly, depending on the ship's draft.

The left side of the Barrel Sheet contains a series of columns with the titles "Time-Rock Unit," "Biostratigraphic Zones/Fossil Character," "Paleomagnetics," "Physical Properties," and "Chenistry." These columns are completed by the appropriate shipboard scientists after the shipboard sedimentologists have completed their part of the Barrel Sheet.

The central part of the Barrel Sheet contains a wide column with the title "Graphic Lithology." This column is bordered to the left by a scale divided into core sections and further sub-divided into $10-\mathrm{cm}$ units, and to the right by three narrow columns with the titles "Drilling Disturbance," "Sed. Structures," and "Samples." The Graphic Lithology column is used to summarize the major sediment types in the core (minor sediment types and other details are not shown), using the letters and numbers of the standard lithologic codes shown in Figure 13. Illustrators then $f 111$ in the matching symbols when the barrel sheets are sent to ODP after the cruise. 


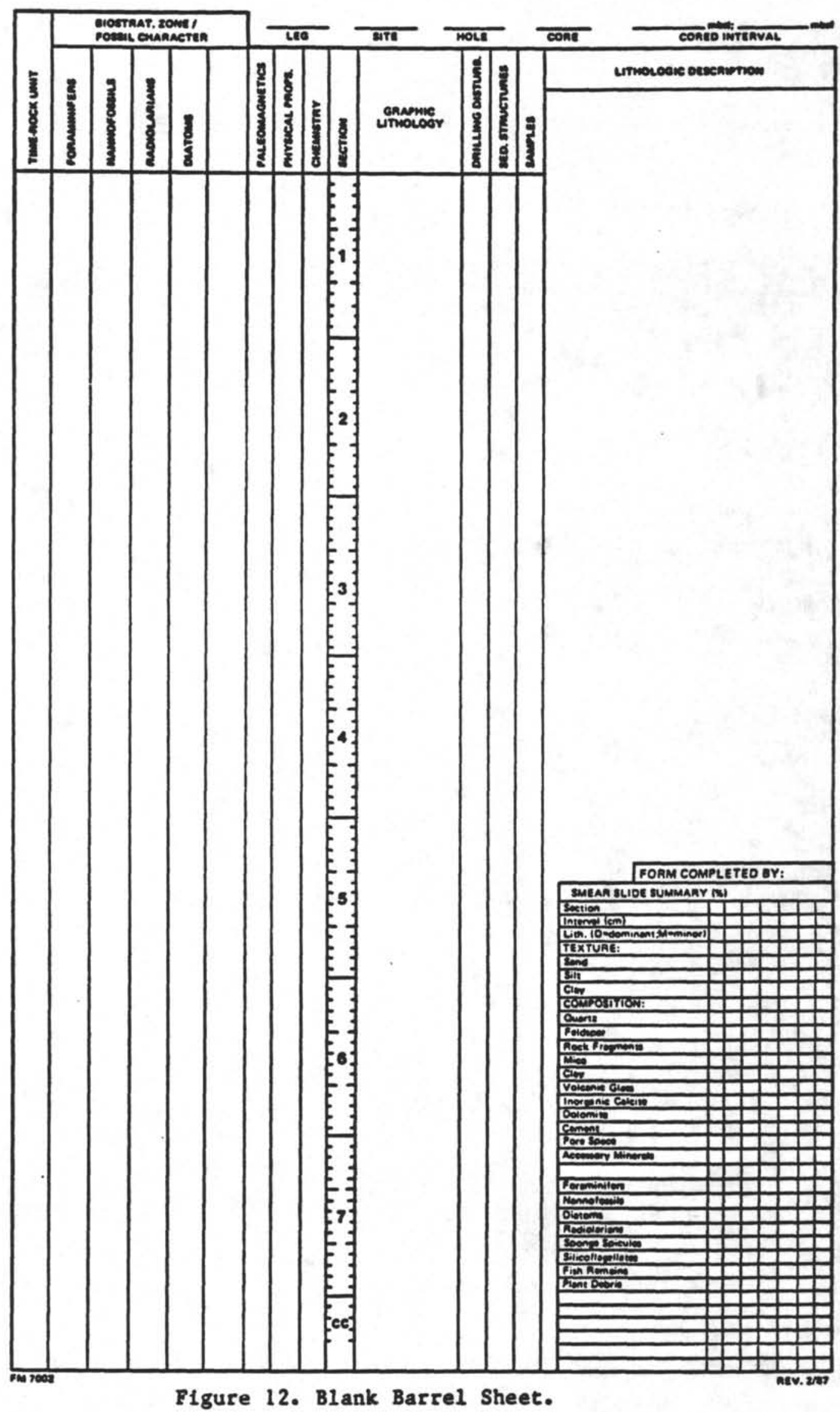


PELAGIC SEDIMENTS

Calcareous

年

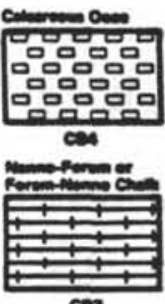

cen
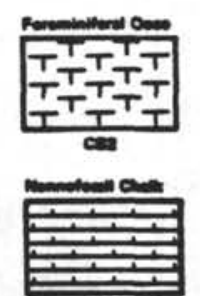

cas

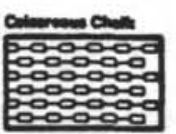

ce

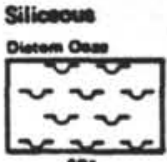

sen

(2)

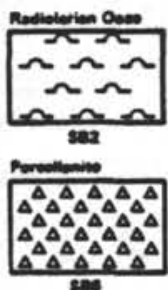

200

NERITIC SEDIMENTS
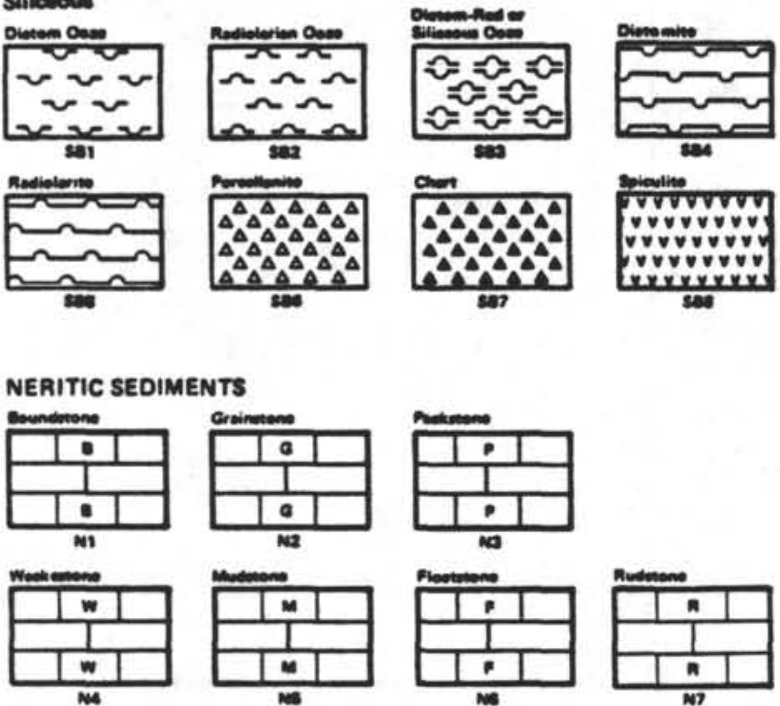

ses
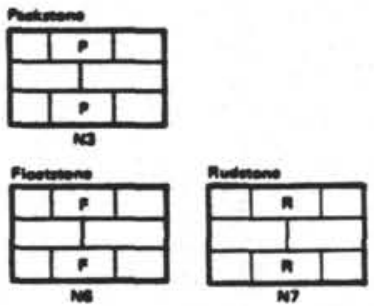

CHEMICAL SEDIMENTS
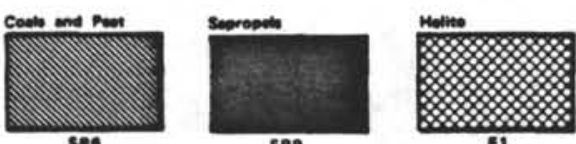

SILICICLASTIC SEDIMENTS
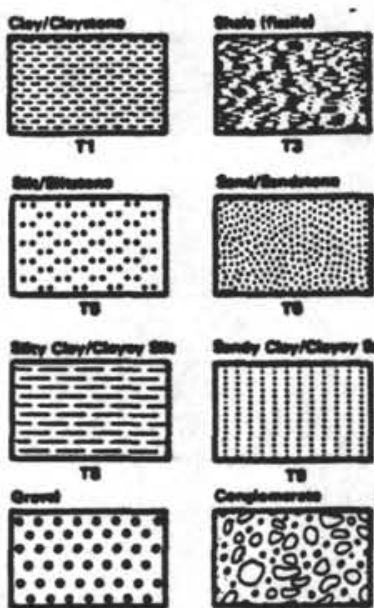

nevar
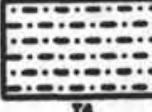

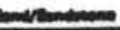

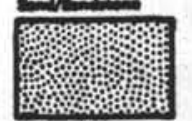

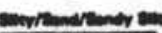

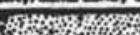

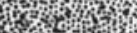

$\pi$

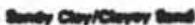

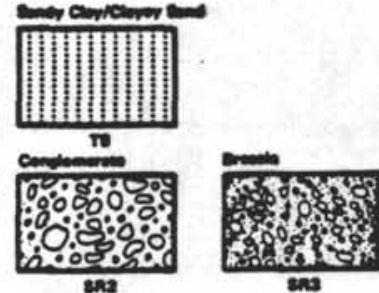

VOLCANICLASTIC SEDIMENTS
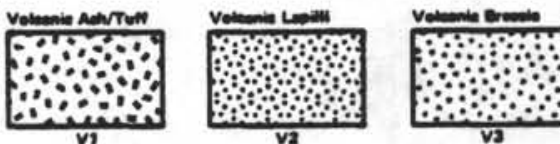

$\therefore \therefore$

MIXED SEDIMENTS

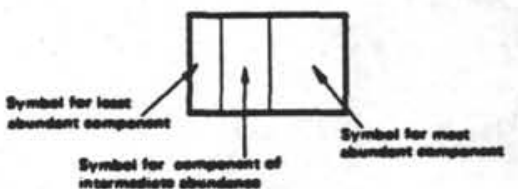

SPECIAL ROCK TYPES
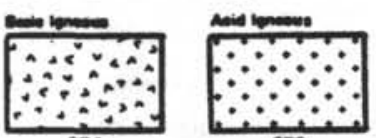

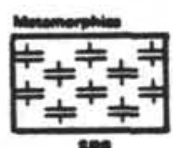

80

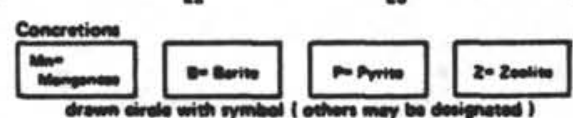

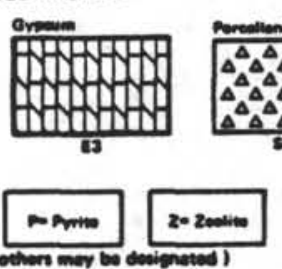

ADOITIONAL SVMBOLS

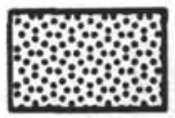

Ast
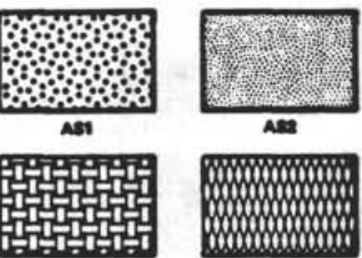

ase

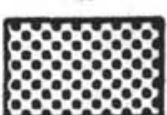

Aต

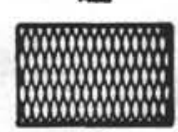

Nan

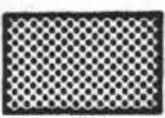

As10
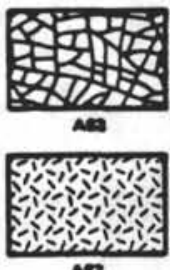

aso

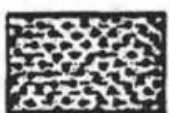

As11
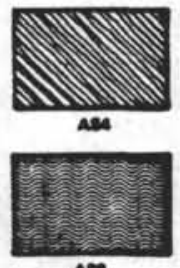

Aต

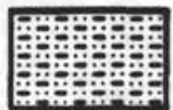

Figure 13. Standard 11thologic codes and symbols used in "Graphic Lithology" column on barrel sheets (see Fig. 12). 
The remaining columns are used to graphically summarize the degree of drilling disturbance, the major stratification features, and the location of routine samples, using the same symbols that were used on the Visual Core Description forms (Fig. 8).

The right side of the Barrel Sheet contains a wide column with the title "Lithologic Description." This column is used for a brief summary of the major and minor lithologies that are present in the core. It includes two sections that are titled "Major Lithologies" and "Minor Lithologies" (both are underlined), and that contain brief descriptions of the lithology (underlined), color (using both descriptive terms and hue-chroma-value alphanumeric data), sedimentary structures, and other pertinent features of the major and minor sediment types in the core. (The descriptions of minor lithologies may also include their exact locations in the cores, if such information is considered useful.) The base of the column contains a small box for the initials of the shipboard sedimentologist who completed the form. All the data in this column must be typed into the shipboard computer system and the diskettes returned to ODP headquarters by the ODP staff scientist, following the cruise. The information in the column should be checked carefully for spelling, completeness, and scientific accuracy; it will be typeset "as is", proofed at the post-cruise meeting, and then published in the Initial Reports volume.

The lower right side of the Barrel Sheet contains a box for summaries of smear slide and/or thin section data, to be compiled by SLIDES or by hand. This box contains columns for seven samples (although commonly, more than seven samples may be analyzed in every core), which should be carefully chosen in order to represent the lithology of all sediment types within that core. The first row of each column provides the section and interval number of each sample (e.g., $3 / 40$ for Section $3,40 \mathrm{~cm}$ ), and the second row indicates whether the sample is a dominant (major) or minor lithology in the core. The remaining rows indicate the texture and composition of each sample (see preceeding discussion).

An example of a completed barrel sheet is shown in Figure 14.

The barrel sheet for a given core should be completed as soon as possible after the core has been described. A routing system can be set up in advance to make sure that the shipboard paleontologists fill in the "Biostratigraphic Zone/Fossil Character" column and pass it on to the other shipboard scientists for completion of the "Paleomagnetics," "Physical Properties," and "Chemistry" columns.

\section{LITHOSTRATIGRAPHIC SECTIONS OF THE HOLE SUMMARIES}

When drilling at a site is finished, the shipboard scientists compile a Hole Summary that contains a series of short chapters by each working group as well as the barrel sheets for all cores. The shipboard sedimentologists provide a chapter on "Lithostratigraphy" for this summary report, which summarizes the general lithology, stratigraphy, and inferred depositional history of the stratigraphic section at the site. For this purpose, the shipboard sedimentologists must first divide the stratigraphic section into discrete units (numbered from the top as I, II, III, etc.) and subunits (A, $B, C$, etc.) on the basis of variations in 1ts lithology and biostratigraphy. Basically, there are no hard-and-fast rules for the definition of units and subunits in a stratigraphic section, but some obvious breaks between them are defined by (1) significant changes in sediment lithology, (2) significant changes in sedimentation rates at the site, (3) significant changes in geophysical properties of the sediments (especially their geophysical $\log$ characteristics), and (4) unconformities. 


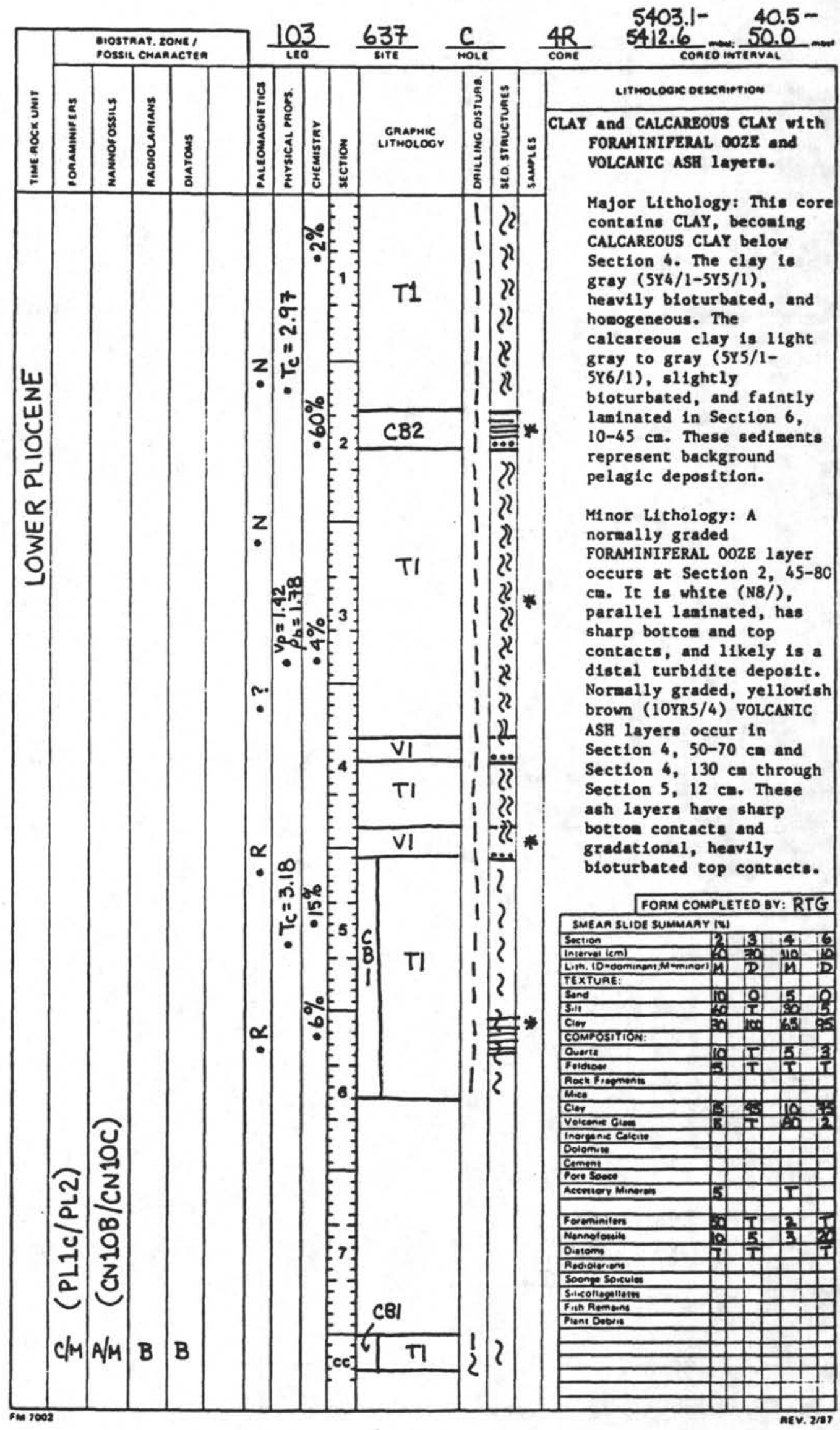

Figure 14. Example of a completed barrel sheet. 
The first part of the "Lithostratigraphy" chapter is usually an "Introduction" containing a brief summary of the overall lithology and age of the stratigraphic section; the number of units and subunits; the general age, lithology, thickness, and distinctive characteristics of each unit and subunit; and other appropriate information.

The second part is usually titled "Description of Units," and contains a series of sections on each unit and subunit. Each section begins with an underlined title that states the unit number, the numbers and sections of the cores in each hole that contain that unit, the age of the unit, and the depth of each unit (in meters below seafloor).

EXAMPLE Unit I: Hole 645A, Core 1H

Hole 645B, Cores $1 \mathrm{X}-18 \mathrm{X}$

Hole $645 \mathrm{C}$, Core $1 \mathrm{X}$-Core $17 \mathrm{X}$, Section 5

Age: Holocene - Pleistocene

Depth: $0-168$ mbsf

If the unit is not divided into subunits, the header is followed by a description of the 1ithostratigraphy which summarizes all the visual core descriptions and petrographic analyses as well as pertinent geochemical, geophysical, and/or paleontological data. If the unit is divided into subunits, the header for the unit is followed by a brief and general description of the unit's lithology and stratigraphy, the definition of the number of subunits within it, and a brief and general description of the lithostratigraphy of each subunit. Following this, each subunit is introduced with its own header (similar to the header for the unit) and is given a detailed description of its lithostratigraphy and other pertinent characteristics.

The third part is usually titled "Interpretation" and is an opportunity for shipboard sedimentologists to interpret the stratigraphic section's origins. This part should begin with a broad interpretation of the entire stratigraphic section, and then proceed to a detailed interpretation of the sedimentation history, depositional environments, and/or diagenetic history of each unit and subunit. The content of this part varies from cruise to cruise. The Co-Chief Scientists may want most interpretation in the "Summary and Conclusions" section, since interpretation usually involves information from other shipboard studies as well.

The "Lithostratigraphy" chapter must be accompanied by a "References" section that lists (in alphabetical order and complete ODP format) all publications cited within the chapter.

Finally, the "Lithostratigraphy" chapter should contain tables and 11lustrations of pertinent data that were collected routinely from the cores (e.g., tables or plots of the carbonate content of pelagic sediments, the mean grain size and sorting of clastic sediments, or the mineralogy of terrigenous clays; pertinent closeup photographs of the cored section; and so on). Of particular value is a table listing the lithologic units, their boundaries (in cores and mbsf), thicknesses, and major characteristics. An example of a composite lithostratigraphy figure showing cored intervals, recovery, 1ithology, and lithologic units is shown in Figure 15a. Examples of other types of data that can be presented in this fashion are shown in Figures 15b-c. 


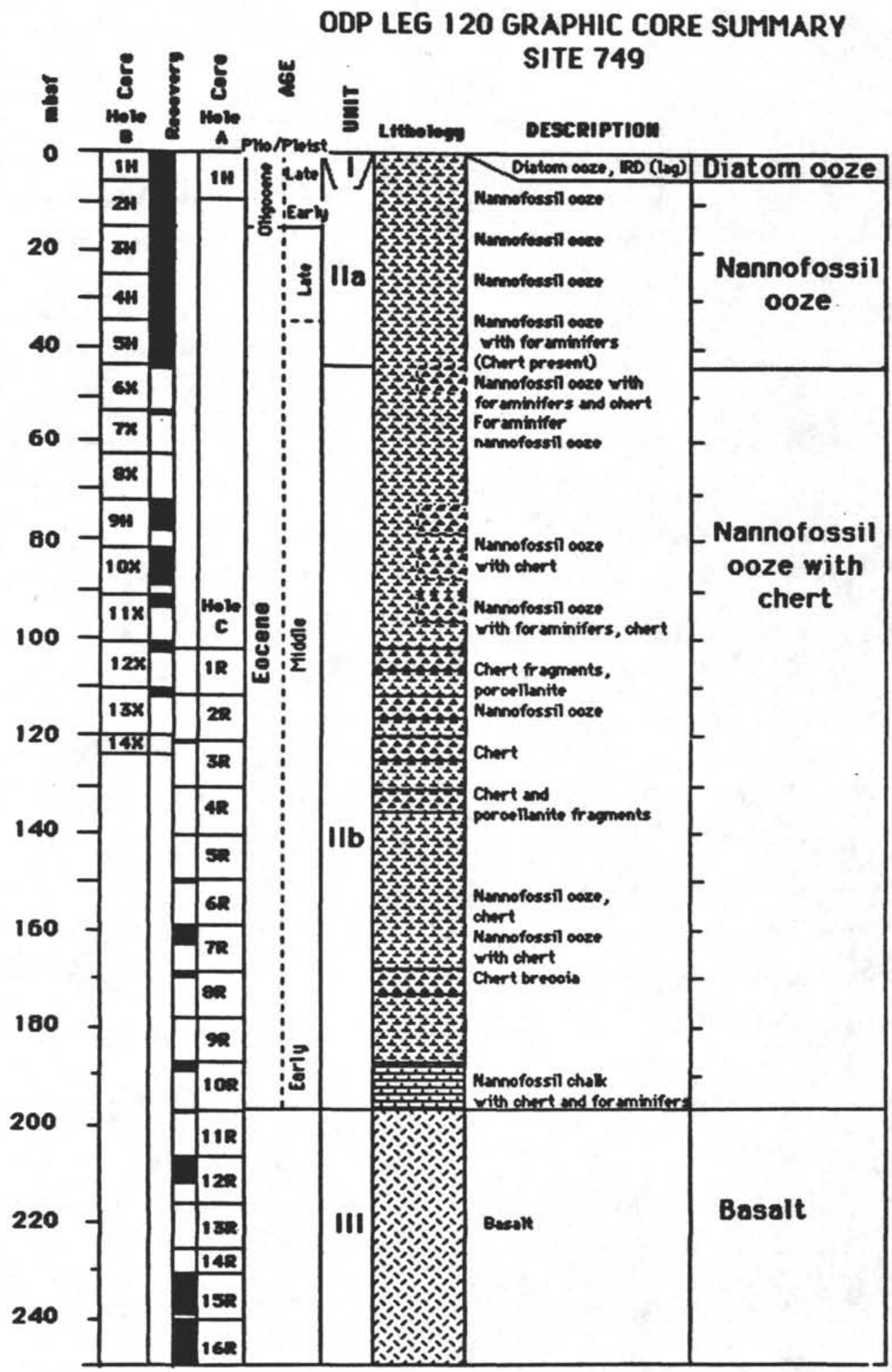

Figure 15a. Cored intervals, recovery, 11thology, and 1ithologic units from Site 749 (Leg 120). 


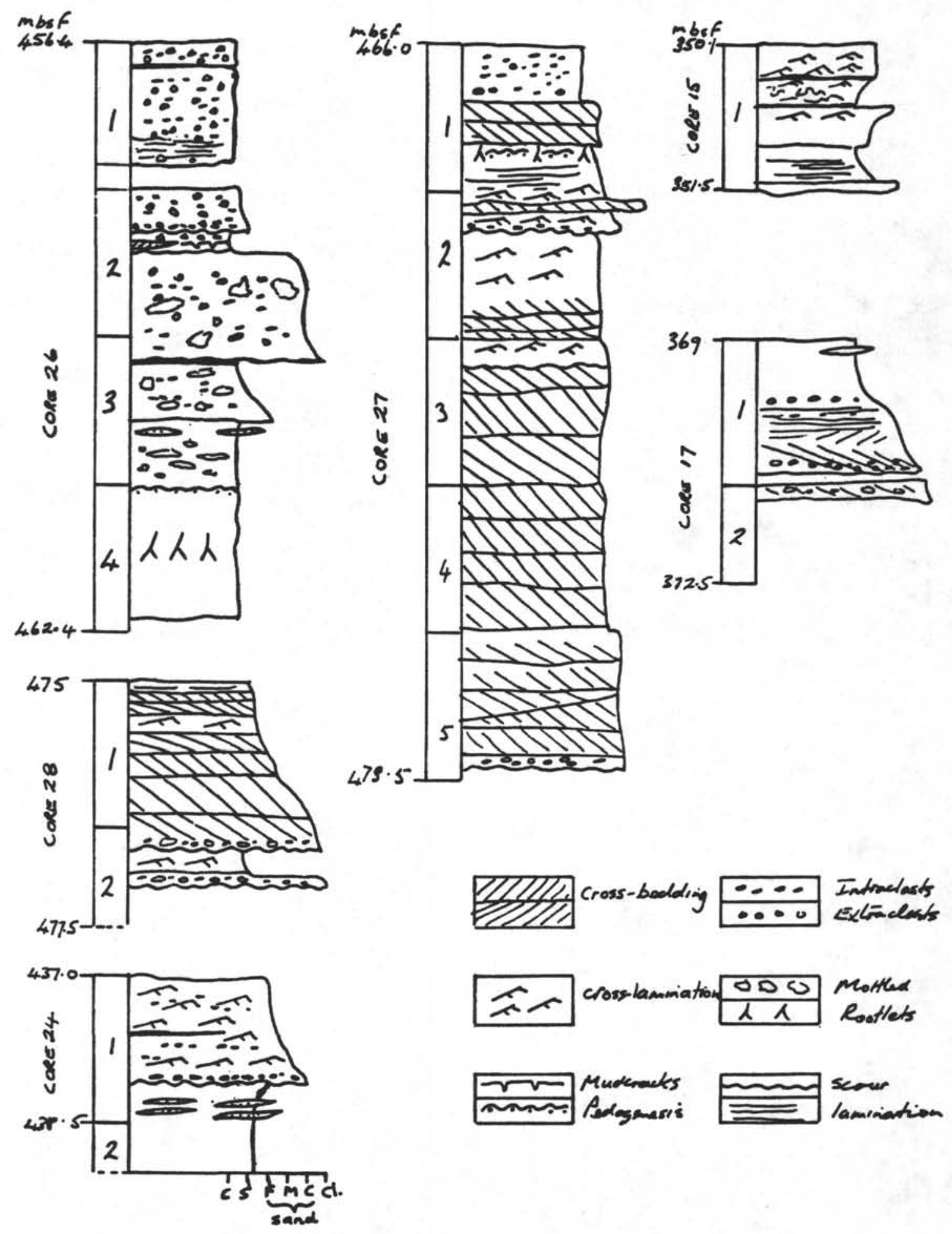

Figure 15b. Sedimentary structures in recovered cores. 


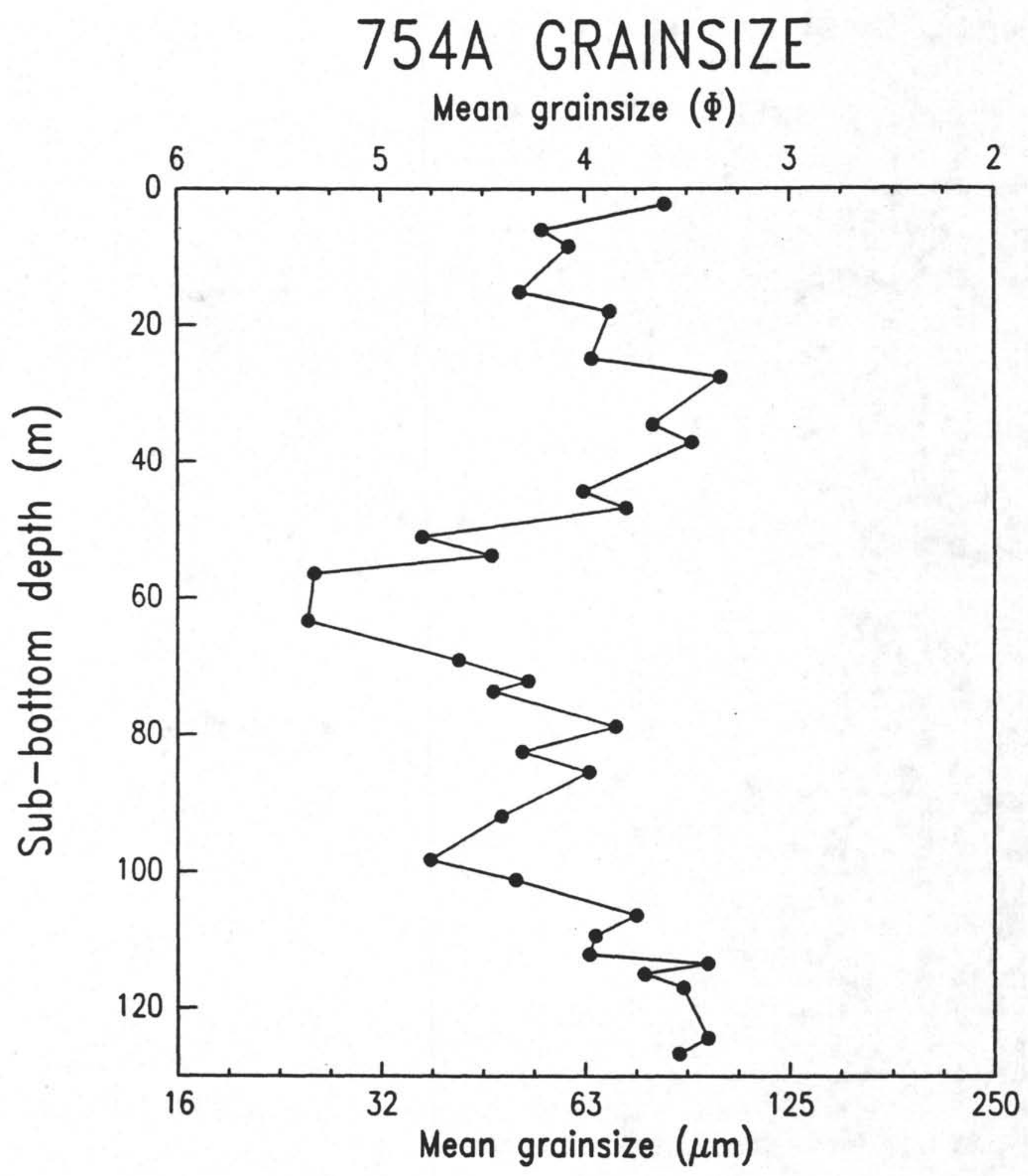

Figure 15c. Plot of grain size data from Hole 754A (Leg 121). 


\section{CHAPTER 4 \\ PROCEDURES AND ANALYTICAL EQUIPMENT}

The laboratories on JOIDES Resolution contain equipment that can be used by the shipboard sedimentologists for lithologic analysis. Generally, four classes of analyses are performed routinely by shipboard sedimentologists and geochemists: (1) petrographic analysis of thin sections, grain mounts, and smear slides; (2) grain-size analysis with a mechanical, laser-operated particle-size analyzer; (3) geochemical analysis of carbonate and organic carbon content; and (4) X-ray-diffraction analysis of mineralogy. In this chapter, we describe the purposes of these analyses, the types of equipment available for them, and the methods of data summary and presentation.

PETROGRAPHIC METHODS OF ANALYSIS

Petrographic analysis is the technique that is used most commonly by sedimentologists to determine the texture and composition of sediments and sedimentary rocks. JOIDES Resolution is equipped with petrographic microscopes and all ancillary equipment and supplies necessary for this purpose.

\section{EQUIPMENT}

The sedimentology laboratory has two Zeiss standard WL petrographic microscopes and two Zeiss SR stereomicroscopes. The lab is also equipped with a hot plate under a benchtop fume absorber, a variety of permanent mounting media (including Canada balsam, Hyrax, Piccolite, Permount, clove oil, gum tragacanth, Norland optical adhesive, and Eukitt, a German synthetic balsam), and supplies (petrographic slides, cover glasses, sieves, sampling tools, etc.) for the preparation of smear slides and grain mounts. The microscope laboratory next to the paleo-prep lab has four additional Zeiss transmitted light microscopes (including two Zeiss Photomicroscope IIIs) that can also be used by the shipboard sedimentologists, in conjunction with the paleontologists and petrologists.

All transmitted light microscopes on the ship have interchangeable objectives $(2.5 x, 10 x, 40 x, 63 x$, and $100 x$ ), ocular pieces (with micrometer scales), and filters. Micrometer slides (for calibrating the ocular scales), reflected-1ight equipment, and TV camera-monitor hook-ups are available. The photomicroscopes accept $35-\mathrm{mm}$ film as well as Polaroid positive (Type 52) and Polaroid positive/negative (Type 55) films.

At the forward end of the sedimentology $1 \mathrm{ab}$, a copystand is set up for closeup core photography (Item 6 in Fig. 2). Closeup photos of designated core intervals for hole summaries and publications may be taken by the shipboard photographer at the request of individual scientists; a request form for this purpose is available in the core lab. The copystand may be used also for closeups for personal research, with scientists' own 35-mm cameras and film; the marine technicians can assist.

There is a limited supply of film for the photomicroscopes and closeup core photography, and this supply is reserved for routine shipboard studies. If you require photographs or photomicrographs for your personal research, you must bring the necessary film with you. The Photography Technician may develop and provide contact sheets of $\mathrm{film}$ on a time-available basis, but will print only closeups and photomicrographs required for the Hole Summaries.

The thin section laboratory has been outfitted to make thin sections manually or automatically, depending upon the number of samples. When one 
or two thin sections are required, they are made manually with a Buehler Petro-thin thin-sectioning system and thin-section grinder. When larger batches of thin sections are requested, they are made with the Logitech system, which includes an LP-30 lapping machine and a WG-2 polishing system. The thin section laboratory is equipped also with a Logitech CS-10 thin-section cutoff saw, a Leco VC-50 varispeed diamond saw, and an IU-20 impregnation unit that can be used to impregnate a coarse-grained sediment sample or a friable and porous sedimentary rock. Both clear and blue-dyed epoxy (which accentuates the pore system) is available. The thin section laboratory is also equipped with a variety of mineral stains, including Methylene blue, Malachite green, Rose bengal, Alizarin red S, Safranin 0, and sodium cobaltinitrite.

\section{PETROGRAPHIC MEDIA}

The 11thology of sediments and sedimentary rocks can be determined by the examination of three types of petrographic media with the petrographic microscope :

1. Smear slides: permanent mounts of fine (silt- and clay-sized) granular sediment. Smear slides are generally made from samples of well-sorted, fine-grained clastic and biogenic sediments (mud, ooze, micrite, etc.). They can also be made from the fine-grained fractions that are mechanically extracted (by sleving) from more poorly sorted sediments.

2. Grain mounts: permanent mounts of coarse (sand-sized) granular sediment. Generally, grain mounts are made from samples of wel1-sorted, coarse-grained clastic and biogenic sediments (sands, grainstones, etc.). They can be made also from the coarse-grained fractions that are mechanically extracted (by sieving) from more poorly sorted sediments.

3. Thin sections: permanent mounts of both granular and chemical sediments. Thin sections can be made from samples of fine-grained and coarse-grained clastic and biogenic sedimentary rocks, from samples of chemical sedimentary rocks, and from artificially impregnated samples of coarse granular sediment.

Common techniques for the preparation of smear slides, thin sections, and grain mounts are described below.

Smear Slides

Preparation of a smear slide requires an extremely small ("toothpick") sample collected either directly from the archive half of the core or from a larger sample that is collected from the working half of the core on the sampling table (see Sampling Methods, below). To make smear slides, the following supplies and equipment are provided:

1. cover glass (24 x $40 \mathrm{~mm})$ - \#1 thickness

2. toothpick

3. water dropper

4. glass petrographic slide $(25 \times 75 \mathrm{~mm})$

5. permanent mounting medium

6. glass rod

7. hot plate

8. tweezers

9. pencil with new eraser

10. slide label

The hot plate is located under a benchtop fume adsorber directly to starboard of the core description table (Item 5 in Fig. 2). The hot plate should be set constantly on "Low." A small beaker or uncapped bottle of 
mounting media is usually kept on (if appropriate, to reduce its viscosity) or near the hot plate under the portable hood at all times. Large bottles of mounting media are kept with the remaining supplies in the cabinet drawers directly below the hot plate; supplies are replenished from the ship's stores by the marine technicians upon request.

Although there are several methods of making a smear slide, most of them are variations on the following. Take a cover glass in hand and place a few drops of distilled water in its center. Collect a tiny fraction of the sample with the flat end of the toothpick, and mix it into the water on the cover glass. Spread the wet sediment with the flat end of the toothpick until it forms a thin translucent coat across the entire cover glass, and then place the cover glass (with the sediment smear up) on the surface of the hot plate to dry.

You will note that this preparation of the smear is inevitably fabric-destructive, and destroys all grain-to-grain and grain-to-cement contacts. Moreover, it can also be grain-destructive, especially to delicate microfossils (e.g., foraminifer tests and coccospheres), but this can be minimized by keeping the sediment sufficiently wet as it is smeared, and by smearing it slowly and gently across the cover glass. In addition, you will note that if the sediment contains some coarse clastic or biogenic grains (e.g., sand, foraminifers, or shell debris), they will be scattered towards the edges of the smear slide and the fine sediment will concentrate in its center. This segregation cannot be prevented easily, and can bias the results of petrographic study (see below).

While the smear on the cover glass dries, place a slide label on the glass petrographic slide, and label it with the leg, site, hole, core, core type, section, and sample interval data. Place a few drops of mounting medium in the center of the petrographic slide with the glass rod, and set it on the surface of the hot plate to warm. When the smear on the cover glass is dry, use the tweezers to place the cover glass (with the sediment smear down) on the mounting medium on the petrographic slide. Press down and slowly rotate the cover glass with the clean eraser-end of the pencil to spread the mounting medium across the petrographic slide and to expel gas bubbles. If there is not sufficient mounting medium to cover the entire smear, use a clean toothpick to drip one or two drops of mounting medium onto the petrographic slide at the edge of the cover glass, where they will be drawn by capillary action under the cover glass. Finally, return the smear slide to the hot plate for 3-5 minutes to allow it to cure.

Grain Mounts

The preparation of a grain mount requires approximately $1-3 \mathrm{~cm}^{3}$ of coarse-grained sediment (depending upon its sorting) collected from the working half of the core on the sampling table (see Sampling Methods, below). This sample should be dried on the hot plate or in the drying oven, and may be sieved with a 63-micron sieve before mounting in order to remove fine-grained detritus. In order to prepare a grain mount, the following

supplies and equipment are provided:

1. petrographic slide $(25 \times 75 \mathrm{~mm})$

2. slide label

3. permanent mounting medium

4. glass rod

5. sleve (optional)

6. toothpick

7. cover glass ( $24 \times 40 \mathrm{~mm})$ 
8. hot plate

9. pencil with new eraser

Place the slide label on the petrographic slide, and fill in the leg, site, hole, core number and type, section, and sample interval. Place the petrographic slide on the hot plate, and use the glass rod to place a few drops of the permanent mounting medium on 1 . Spread the mounting medium across the slide, and allow any bubbles to escape. The mounting medium should be spread thickly, so that all the grains will settle into 1 t.

Once the sample is dried (and sleved if necessary), the grains should be sprinkled onto the petrographic slide and then spread evenly across the slide with the flat end of the toothpick. Allow the grains to settle into the mounting medium (adding a few more drops of mounting medium with the glass rod if necessary), and then place the cover glass over the mount. Press down and slowly rotate the cover glass with the clean eraser-end of the pencil to spread the mounting medium across the petrographic slide and to expel gas bubbles. If there are large bubbles present in the mount, place one or two drops of mounting medium on the petrographic slide at the edge of the cover glass, and they will be drawn by capillary action under the cover glass. Finally, keep the grain mount on the hot plate for 3-5 minutes to allow it to cure, and then remove it and allow the mount to cool.

Thin Sections

Preparation of a thin section from a granular or chemical sedimentary rock can be prepared in two ways: as a coarse-grain mount or as an artificially impregnated thin section. Preparation of a coarse-grain mount requires a 1-2-cm-thick quarter-wedge that is collected from the working half of the core on the sampling table. This sample must be dried on a hot plate or in the drying oven and it may be sieved to remove fine-grained detritus. A thin section from an artificially impregnated coarse sediment requires $3-5 \mathrm{~cm}^{3}$ of sample (depending upon sorting), and is made like a hard-rock thin section, preserving bedding structure.

A marine technician assigned to the thin-section laboratory produces thin sections from lithified or nonlithified samples at the written request of the shipboard sedimentologists. When requesting a thin section, the shipboard sedimentologists must specify (1) the desired thickness of the thin section, (2) the type (clear or blue) of epoxy (when appropriate), (3) whether a permanent cover glass should be affixed, or (4) any other special procedures.

Thin sections can be made without a permanent fixed cover glass so that stains can be applied later. During petrographic examination, the thin section can be coated with a temporary mounting medium (glycerin or mineral oil) and covered with a cover glass, but this cover glass should be removed and the thin section cleaned in soapy water after examination.

The thin section laboratory is supplied with a variety of stains that can be used to facilitate the identification of minerals in thin sections. This staining can be done under the hoods in the chemistry laboratory by the shipboard sedimentologist or a marine technician.

The most commonly used stain for carbonate sedimentary rocks is Alizarin red $S$, which is an effective stain for calcite. The procedure for the staining of a thin section with Alizarin red $S$ is as follows:

1. prepare a solution of Alizarin red $S$ by dissolving $0.1 \mathrm{gram}$ of Alizarin red S (solid) in 100 milliliters of $0.2 \%$ hydrochloric acid of commercial grade; 
2. place the thin section in dilute $(0.1 \%)$ hydrochloric acid of commercial grade for 2-3 minutes, or until some relief can be seen on its surface with a hand lens or a binocular microscope;

3. pour the Alizarin red $S$ solution into a shallow pan, and soak the thin section in this solution for 1-3 minutes.

The calcite will be stained a deep red color by the Alizarin red S within 3 minutes, while dolomite will remain unstained. After petrographic examination, wash the stain from the surface of the thin section with soapy water.

A common stain for clastic sedimentary rocks is sodium cobaltinitrite, which is an effective stain for potassium feldspar. The procedure for the staining of a thin section with sodium cobaltinitrite is as follows:

1. prepare a $5 \%$ solution of barium chloride;

2. pour concentrated (52\%) hydrofluoric acid into an etching vessel to within $5 \mathrm{~mm}$ of the top, and place the thin section (rock slab down) across the top of the etching vessel for 1 minute, or until some relief can be seen on its surface with a hand lens or a binocular microscope.

CAUTION: Before hydrofluoric acid is used, the Operations Superintendent and Co-Chief Scientists must be notified. They will notify the Captain, who may require that the ship's heading be changed so that adequate ventilation is achieved. Hydrofluoric acid may be used only under certain designated fume hoods, and use may be restricted in certain weather conditions. Only very limited quantities are kept aboard ship.

3. remove the thin section, dip it quickly into distilled water, dip it quickly twice into the barium chloride solution, and then rinse with distilled water;

4. pour the sodium cobaltinitrite solution into a shallow pan, and immerse the thin section into this solution for 1 minute;

5. remove the thin section and rinse with distilled water. The potassium feldspar will be stained bright yellow;

6. (Optional) immerse the thin section in rhodizonate reagent $(0.05 \mathrm{gm}$ of rhodizonic acid potassium salt dissolved in 20 milliliters of water), which will stain the plagioclase feldspar yellow.

A description of other stains and staining techniques can be found in Robert Carver's "Procedures in Sedimentary Petrology," which is in the shipboard library.

All staining must be done under a hood to prevent the escape of acid fumes in the laboratory, and use of hydrofluoric acid requires a specially designated fume hood.

\section{PETROGRAPHIC METHODS}

Two properties of a sediment or sedimentary rock can be examined and described with the petrographic microscope: texture (in granular sediments) and composition (In granular and chemical sediments). The texture of grains can be measured with the aid of the micrometer scale on the ocular eyepiece of the petrographic microscope, which is calibrated with a micrometer slide. The composition of sediments is determined by their optical properties (form, color, relief, extinction, birefringence, cleavage, and so on) in plane and polarized light.

The sedimentology laboratory contains a file of smear slides and thin sections of different types of sediment types (e.g., ooze, sand, 
grainstone), minerals (e.g., quartz, apatite, glass), and biogenic grains (e.g. forams, radiolarians, diatoms), which are an excellent source of reference. We strongly recommend (especially to first-time shipboard sedimentologists) that you examine these reference slides and become familiar with their components before you reach the first drilling site.

\section{Texture}

The first step in a shipboard petrographic analysis is to estimate the texture of clastic and biogenic grains (when present) in the sample. This can be done by two techniques: visual estimation and point-counting.

The visual estimation technique uses a standard visual comparison chart to estimate the relative abundances of sand, silt, and clay (Fig. 16). For this purpose, it is important to note the equivalent 63-micron length (the boundary between sand and silt) and the equivalent 4-micron length (the boundary between silt and clay) on your ocular eyepiece scale.

The point-counting technique uses the ocular eyepiece scale to measure the long axis (or any other dimension) of individual clastic and biogenic grains. Generally, the size of only one biogenic grain type (e.g., forams) or clastic mineral type (e.g., quartz) is measured in the samples in order to minimize any size variation that may be a function of compositional variation. In point-counting, the smear slide, grain mount, or thin section is scanned across its length, and the size of every targeted grain type that is intersected by the cross-hairs is measured (this is called the "ribbon method" of point-counting). Point-counting should proceed until 50 and 200 grains have been measured in the sample, and the resultant data should be used to calculate mean grain size and sorting.

Point-counting is much more time-consuming than visual estimation of sediment texture and is only done if time permits and scientific need dictates. Textural data can also be derived from a particle-size analyzer available aboard ship (see below).

\section{Composition}

The second step in petrographic analysis is estimating the composition of the sample. Once again, this can be done by visual estimation and pointcounting, but the point-counting should use the Glagolev-Chayes method, rather than the ribbon method, to select grains for study. In the GlagolevChayes method, the composition of the sediment is analyzed at a series of equally spaced points along a line, rather than continuously along the line (as in the ribbon method) (Fig. 17). This point-counting method determines the area percentage of the various grain and cement components, and is a good estimate of their relative volumes in the sediment.

Comparison of Visual Estimates and Point-Counting

The visual estimation technique is rapid, and is consequently useful for the petrographic analysis of a large suite of samples. However, it is also subject to varying degrees of operator bias and error, the greatest source of which is the "memory effect" - that is, the operator uses visual comparison charts to estimate relative abundances of textural classes and grain and cement types with diligence for the first few samples, and then relies upon his/her memory of the visual comparison from that point onward (Griffiths, 1967). In attempts to minimize this source of error, visual comparison charts are posted directly behind the petrographic microscopes, where they can be seen by the operator during petrographic analysis. 
Comparison Chart For Visual Percentage

Estimation (After Terry and Chilingar, 1955).
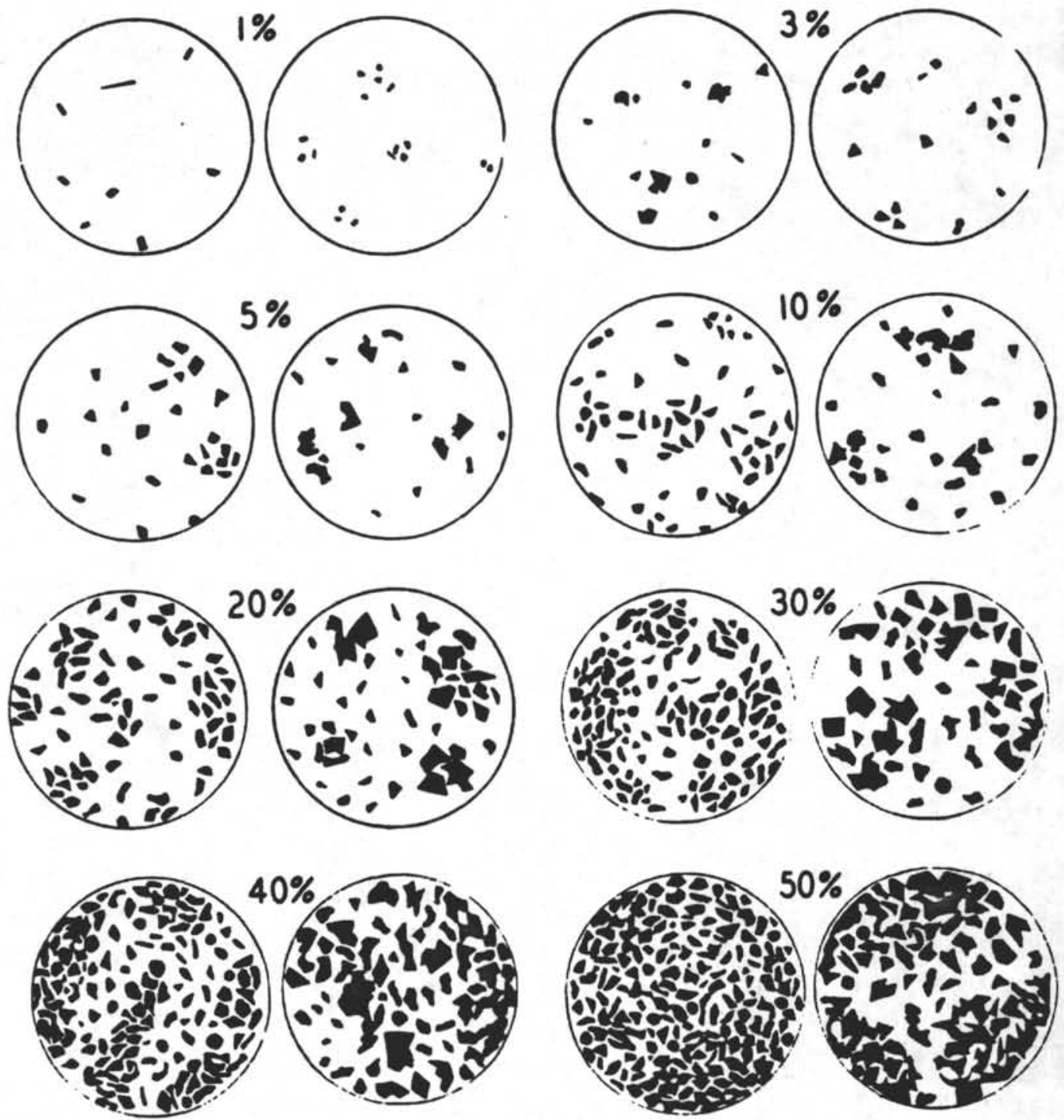

Figure 16. Comparison chart for visual percentage estimation (after Terry and Chilingarian, 1955). 


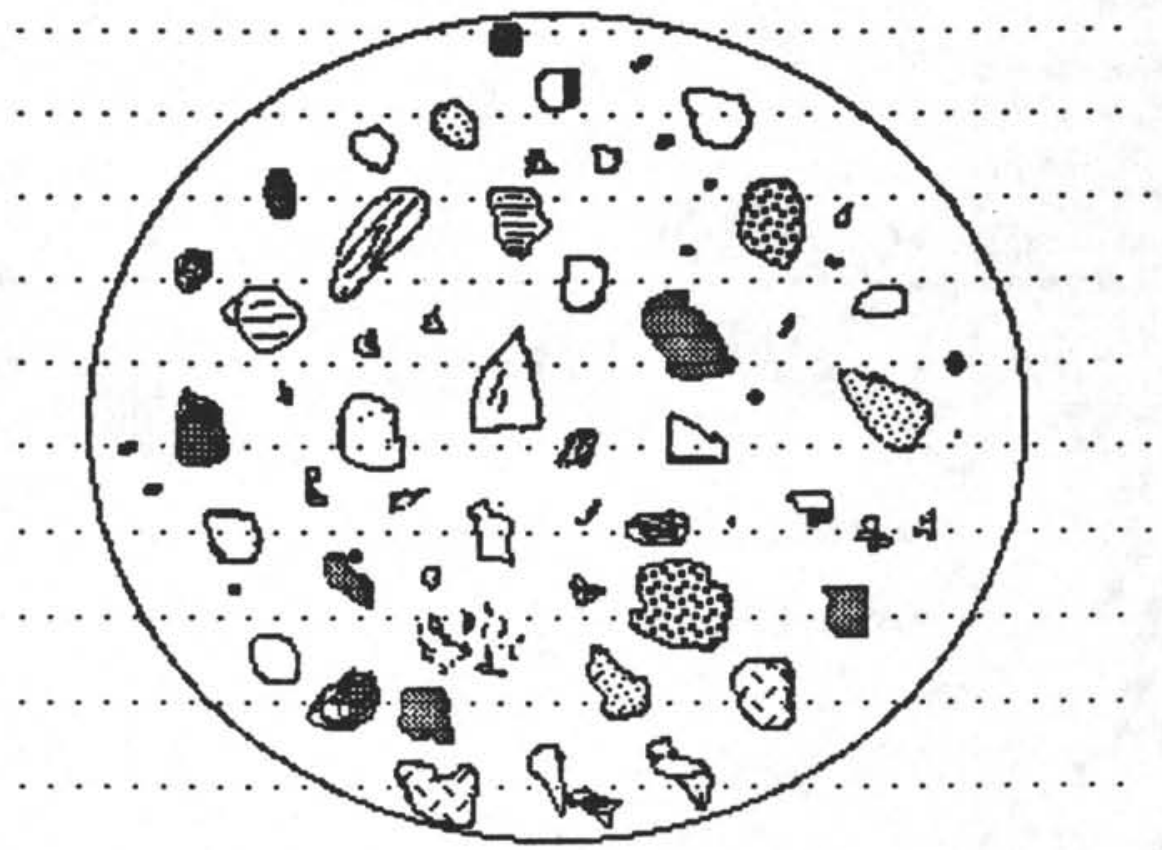

Figure 17. Example of the Glagolev-Chayes point-count method. 
The error in visual estimation can also be increased by factors related to the sample preparation process, and particularly to the preparation of smear slides. There are two sources of error inherent in smear slides:

1. the segregation of grain sizes. It was previously noted that the preparation of smear slides of poorly sorted sediment will segregate coarse from fine grain sizes. Thus, if the operator scans only the center of the smear slide and ignores its perimeter (or vice versa), he/she will have a biased view of both the texture and the composition (which is a function of texture) in the sample.

2. the thickness of the smear. The use of the visual comparison chart assumes that the petrographic image that is being examined by the operator is entirely filled with grains, cement, or matrix. However, if a smear slide is too thin and diffuse, it will have a large amount of void space, while if it is too thick, the grains will be stacked one upon another. In either case, it will be difficult to correctly estimate the relative abundances of textural classes and grain and cement types with the visual comparison charts.

The point counting technique is slow, and usually can be used only on a smaller suite of select samples. It is particularly useful for the compositional analysis of coarse-grained clastic and biogenic sediments, and for the textural analysis of coarse-grained clastic sediments.

\section{GRAIN-SIZE ANALYSIS BY PARTICLE-SIZE ANALYZER}

A Lab Tec 100 particle size analyzer (PSA) is available aboard ship for use by shipboard sedimentologists to provide rapid percentage measurements of silt- and clay-sized particles to aid in smear slide interpretation. This equipment uses a focused laser diode light source ( $0.8 \times 2.0$ microns) to measure the sizes of individual particles in solution. The PSA can be operated in efther of two size ranges: $250-<4$ microns and $125-<2$ microns, respectively, with eight size intervals measured for each range. The particle size is determined by the length of time a particular particle takes to pass through the laser beam. Since the beam is scanned at a constant velocity normal to the direction of fluid flow, the particle size is determined by

$$
\mathrm{D}=\mathrm{VT}
$$

where $D=$ size of the particle, $V=$ scanning velocity of the beam, and $T=$ time that the particle is in the beam.

\section{GEOCHEMICAL AND X-RAY-DIFFRACTION ANALYSIS}

The petrographic microscope is well suited for the study of the composition of coarse-grained clastic and biogenic sediments and sedimentary rocks. However, it is less rellable and precise for fine-grained clastic and blogenic sediments and sedimentary rocks, because the grains are close to or below its limits of resolution. For this reason, the petrographic analysis of fine-grained sediments and sedimentary rocks must be supplemented with other, more precise analytical techniques.

The two supplementary analytical techniques that must be used on fine-grained sediments and sedimentary rocks are (1) geochemical analysis of carbonate content and organic carbon content, and (2) X-ray-diffraction analysis. The former technique must be routinely applied to all pelagic sediments and fine-grained marly sediments in order to measure the relative 
abundance of calcareous and noncalcareous detritus; the latter technique must be routinely applied to all fine-grained clastic sediments and fine-grained marly sediments in order to determine the mineralogy of the clastic detritus. These two techniques can also be employed on other types of sediments at the discretion of the sedimentologist. For example, we strongly recommend that the carbonate content of coarse-grained marly sediments and sedimentary rocks be measured in order to gauge the relative abundance of calcareous and clastic detritus.

The laboratories aboard JOIDES Resolution are well equipped for geochemical analysis and X-ray-diffraction analysis. The chemistry laboratory, for example, is equipped with a Delsi Nermag Rock-Eval II Plus TOC, which evaluates the type and maturity of organic carbon, calculates petroleum potential, and detects oil shows; a Perkin-Elmer CHNS Elemental Analyzer, which automatically measures the amount of organic carbon, hydrogen, nitrogen, and sulfur in up to 60 samples at a time; a Coulometric Analyzer, which accurately measures the carbonate content of sediment; a Labconco 339 -port freeze drier, which removes water from sediment samples up to $15 \mathrm{~cm}^{3}$ in size; Cahn 29 and Scientech balances for accurately weighing small and large samples; agate mortars and grinders and a hardened-steelball Spex mill grinder for homogenized dried sediment samples; a Barnstead water purifier, which produces 100 liters of both lab and reagent grade water by osmotic pressure; and three fume hoods for solvents and chemical reactions (see ODP Technical Notes 6 and 7 for further information).

The X-ray laboratory is equipped with a Philips ADP 3520 X-ray diffractometer. This instrument is fully automated, has auto-sample loading, and is supported by a DEC Micro-11 computer with a 28-megabyte disk drive. The computer software includes quantitative and qualitative analyses, search-match of JCPDS and user data bases, line profile analysis, and statistical analysis programs. The laboratory is also equipped with an Applied Research Laboratory 8400 hybrid spectrometer for X-ray fluorescence and elemental analysis (which is not generally used for sediments and sedimentary rocks), and a variety of devices for sample disaggregation and sample fusion.

The chemistry laboratory is staffed by marine technicians who prepare, run, and analyze routine samples. On the basis of decisions by the Co-Chief Scientists at their pre-cruise meeting, the X-ray laboratory may be run either by dedicated marine technicians or by members of the shipboard party who are trained by the marine technicians. In general, the responsibility of the shipboard sedimentologists is to select the location and size of samples to be analyzed.

\section{SAMPLING METHODS AND ANALYTICAL PROCEDURES}

The types of analyses that are conducted on sediments and sedimentary rocks, and the sizes of samples for these analyses, vary with composition.

For pelagic sediments, two types of analyses are required: geochemical analysis and petrographic analysis. The former analysis is used to determine the relative abundance of carbonate and organic carbon in the sediment; the latter analysis is used to determine the texture and relative abundance of biogenic and clastic grains. The petrographic media are generally smear slides, but thin sections may be used for well-lithified sediments.

For neritic and coarse-grained clastic sediments, a petrographic analysis of sediment texture and composition is the only required analysis. 
The most common medium for this analysis is the thin section, but grain mounts may also be used for poorly consolidated sediment.

For fine-grained clastic sediments, two types of analyses are required: $\mathrm{X}$-ray diffraction and petrographic analysis. The former analysis is used to determine the composition of the sediment, and the latter is used to determine the texture and relative abundance of clastic minerals and biogenic grains. The petrographic medium is generally smear slides, but thin sections may also be used for well-lithified sediments.

For coarse-grained mixed sediments, a petrographic analysis of sediment texture and composition (in thin section or grain mounts) is the only required analysis. For fine-grained mixed sediments, three types of analysis are required: $X$-ray analysis (for the composition of the fine clastic grains), geochemical analysis (for carbonate and organic carbon content), and petrographic analysis of smear slides or thin sections (for overall texture and composition).

For chemical sediments, a petrographic analysis of sediment composition in thin section is the only required analysis.

\section{SAMPLING METHODS}

The analysis of pelagic sediment requires approximately $5 \mathrm{~cm}^{3}$ of sample, and this sample must be collected from the working half of the core on the sampling table. The sedimentologist uses a small flag marked "SED/CHEM" (available on the sampling table) to pinpoint the position of the sample in the working half. The sample is collected by the scientists on the sampling shift and entered into SAM, the computer sampling data base. This sample is placed in a small bag or aluminum tray labeled with the leg, site, hole, core type, section, and sample interval, and is set aside for the sedimentologist. The sedimentologist uses the flat end of a toothpick to collect a small piece of the sample for smear slide preparation, and passes the remainder of the sample in its tray to the chemistry laboratory technicians for geochemical analysis.

The analysis of neritic sediment, coarse-grained clastic sediment, coarse-grained mixed sediment, and all types of chemical sediments requires the collection of a $2-\mathrm{cm}$-thick quarter-wedge of sediment (for thin sections) or a $1-3-\mathrm{cm}^{3}$ plug of sediment (for grain mounts) from the working half of the core. The location of the desired sample is noted on the working core by a small flag marked "SED/PET," and the sample is collected by the scientists on the sampling shift. This sample is placed in a sample bag that is marked with the leg, site, hole, core, core type, section, and sample interval, and will be set aside for the sedimentologist. If the sample is to be thin-sectioned, it should be passed directly to the thin section laboratory technician. If it is to be grain-mounted, the sample should be removed from the sample bag, placed in a marked aluminum sample tray, dried on the hot plate or in the drying oven, and sieved to remove any fine-grained sediment (which may be separately studied in smear slide). 3 The analysis of fine-grained clastic sediment requires approximately 5 $\mathrm{cm}^{3}$ of sample that is collected from the working half of the core. The location of the desired sample is noted on the working half by a small flag that is marked "SED/XRD," and is collected by the Curatorial Representative or his/her assistants. This sample will be placed in a sample bag (appropriately marked), and will be set aside for the sedimentologist. The sedimentologist will use the flat end of the toothpick to collect a part of the sample for smear slide, and the remainder of the sample will be sent to the $\mathrm{X}$-ray laboratory technician for analysis. If a thin section is to be 
made from the sediment, a $10-\mathrm{cm}^{3}$ sample should be bagged and sent to the $X$-ray laboratory technician; the second half should be bagged and sent to the thin-section laboratory technician.

The analysis of $\mathrm{f}$ ine-grained nonclastic sediments requires

approximately 5-10 $\mathrm{cm}^{3}$ of sample that is collected from the working half of the core. The location of the desired sample is noted on the working half by a small flag that is marked efther "SED/XRD" or "SED/CHEM." The sample should be split in half after sampling. One half of the sample should be placed in a labeled aluminum tray, sampled for smear slide analysis, and passed on to the chemistry laboratory technicians; the second half should be bagged and sent to the $X$-ray laboratory technicians. If a thin section is made of the sediment, a larger $\left(20 \mathrm{~cm}^{3}\right)$ sample will have to be collected from the working half.

There are two things to note about the sampling procedures. First, whenever there are two or more analyses to be conducted on the sediment, they should all be conducted on a split of the same sample. Second, the archive half of the core which is being described by the shipboard sedimentologists should not be sampled for any routine lithologic analysis. The archive half may be scraped for a smear slide in order to determine the general lithology of the sediment (if it is not readily apparent). However, once this determination is made, a larger sample must be collected from the working half of the core for the full complement of petrographic, geochemical, and/or X-ray analyses.

Please note that all smear slides, grain mounts, and thin sections are the property of the Ocean Drilling Program, and are collected by the Curatorial Representative at the end of drilling at each site. However, any of these petrographic slides can be requested for further shore-based analysis on loan from the Curatorial Representative.

\section{REFERENCES}

Griffiths, J. C., 1967. Scientific Method in Analysis of Sediments: New York (McGraw-Hi11).

Harms, J. C., Southard, J. B., and Walker, R. G., 1982. Structures and sequences in clastic rocks: Lecture notes for Short Course 9, Soc. Econ. Paleontol. Mineral.

McKee, E. D., and Weir, G. W., 1953. Terminology for stratification and cross-stratification in sedimentary rocks. Geol. Soc. Am. Bull., $64: 381-390$.

Terry, R. D., and Chilingarian, G. V., 1955. Summary of "Concerning some additional aids in studying sedimemtary formations" by M. S. Shetsov. J. Sed. Petrol., 25:229-234. 
APPENDIX I

NEW SEDIMENT CLASSIFICATION SCHEME

FOR THE OCEAN DRILLING PROGRAM

by

Jim Mazzul1o1,2, Audrey Meyer ${ }^{2,3}$, and Robert Kidd ${ }^{4}$.

1 Department of Geology, Texas A \& M University

2 Ocean Drilling Program, Texas A \& M University

3 Department of Oceanography, Texas A \& M University

${ }^{4}$ Department of Earth Sclences, University College of Swansea, U.K. 


\section{INTRODUCTION}

The Deep Sea Drilling Program (DSDP) employed a sediment classification scheme that was devised by the JOIDES Panel on Sedimentary Petrology and Physical Properties and adopted for use by the JOIDES Planning Committee in March of 1974. That JOIDES classification scheme was put into service on DSDP Leg 38, and was also used by the Ocean Drilling Program (ODP) through 1987; it is fully described in the various Initial Reports of the Deep Sea Drilling Program (see, for example, Ross et al., 1978).

The DSDP concentrated its early drilling effort in deep marine sedimentary environments for various scientific and technical reasons, and thus the JOIDES sediment classification scheme evolved with strong emphasis upon the proper classification of fine-grained calcareous and siliceous ("pelagic") sediments. However, the weakness of the JOIDES classification scheme--its lesser emphasis upon the classification of coarse-grained carbonate ("neritic"), clastic, and mixed sediments--became apparent as DSDP and ODP expanded the ocean-drilling effort to continental margins and marginal seas, and resulted in its modification in a variety of ways by the shipboard scientists on most DSDP and ODP legs to date. For example, the Leg 101 shipboard scientists found that the JOIDES classification scheme did not precisely classify coarse-grained carbonates, which were a major component in their cores; thus they amended the Dunham (1962) classification scheme for such sediments to the JOIDES classification scheme to meet their needs.

The purpose of this paper is to describe a more comprehensive sediment classification scheme for the Ocean Drilling Program which places equal emphasis upon pelagic, neritic, clastic, and mixed sediments, and thereby responds to the growing need for the precise description of sediments from continental-margin and marginal-sea environments. This sediment classification scheme is a revision of the original JOIDES sediment classification scheme, but also adopts some modifications to the same that were proposed by Dean et al. (1985). This new scheme was approved by the JOIDES Sediments and Ocean History Panel in 1987 for shipboard use.

This new classification scheme is a descriptive rather than genetic classification, for it classifies sediments on the basis of their textures and compositions rather than their assumed or postulated genesis. It provides a consistency of classification and nomenclature that will allow for easier communication between scientists and greater efficiency in the acquisition, storage, and retrieval of sedimentological data from the ODP computerized data-storage system.

\section{BASIC SEDIMENT TYPES}

The sediment classification scheme described here defines two basic sediment types: (1) granular sediment and (2) chemical sediment. Granular sediment is composed of discrete grains of organic (e.g., foram tests, mollusc shells) or inorganic (e.g., quartz grains, rock fragments, volcanic ash) origins that were deposited by physical or organic processes. Some examples of granular sediment are foraminiferal chalk, quartz sandstone, vitric ash, and oolitic grainstone. Chemical sediment is composed of minerals that formed by inorganic processes such as precipitation from 
solution or colloidal suspension, deposition of insoluble precipitates, or recrystallization of detrital evaporites and siliceous, calcareous, or carbonaceous ( $p l a n t$ ) biogenic debris, and generally has a crystalline (i.e., non-granular) texture. Some examples of chemical sediment are coal, halite, pyrite, and gypsum.

Separate sediment classification schemes have been devised for granular and chemical sediments, for there are great differences in the 1ithologies, fabrics and depositional histories of these two basic sediment types even when they are present together in the same sediment sample.

\section{CLASSIFICATION OF GRANULAR SEDIMENTS}

Classes of Granular Sediments

There are four types of grains that can be found in granular sediments: pelagic, neritic, siliciclastic, and volcaniclastic grains. Pelagic grains are composed of the fine-grained organic debris of open-marine siliceous and calcareous microfauna and microflora (e.g., radiolarians, nannofossils) and associated organisms. Neritic grains are composed of coarse-grained calcareous skeletal debris (e.g., shell fragments), coarse-grained calcareous non-skeletal debris (e.g., ooids, peloids), and fine-grained calcareous grains of non-pelagic origin (e.g., micrite). Siliciclastic grains are composed of mineral and rock fragments that were derived from plutonic, sedimentary, and metamorphic rocks. Volcaniclastic grains are composed of rock fragments and minerals that were derived from volcanic sources.

Variations in the relative proportions of these four grain types define five major classes of granular sediments: pelagic, neritic, siliciclastic, volcaniclastic, and nixed sediments (Figure 1 ).

Pelagic sediments are composed of more than $60 \%$ pelagic and neritic grains and less than $40 \%$ siliciclastic and volcaniclastic grains, and contain a higher proportion of pelagic than neritic grains (Appendix, Examples 1-9).

Neritic sediments are composed of more than $60 \%$ pelagic and neritic grains and less than $40 \%$ siliciclastic and volcaniclastic grains, and contain a higher proportion of neritic than pelagic grains (Appendix, Examples 10-13).

Siliciclastic sediments are composed of more than $60 \%$ siliciclastic and volcaniclastic grains and less than $40 \%$ pelagic and neritic grains, and contain a higher proportion of siliciclastic than volcaniclastic grains (Appendix, Examples 14-19).

Volcaniclastic sedinents are composed of more than $60 \%$ siliciclastic and volcaniclastic grains and less than $40 \%$ pelagic and neritic grains, and contain a higher proportion of volcaniclastic than siliciclastic grains (Appendix, Examples 20-22). This class includes epiclastic sediments (volcanic detritus that is produced by erosion of volcanic rocks by wind, water, and ice), pyroclastic sediments (the products of the degassing of magmas), and hydroclastic sediments (the products of the granulation of volcanic glass by steam explosions). 
RATIO OF SILICICLASTIC TO VOLCANICLASTIC GRAINS

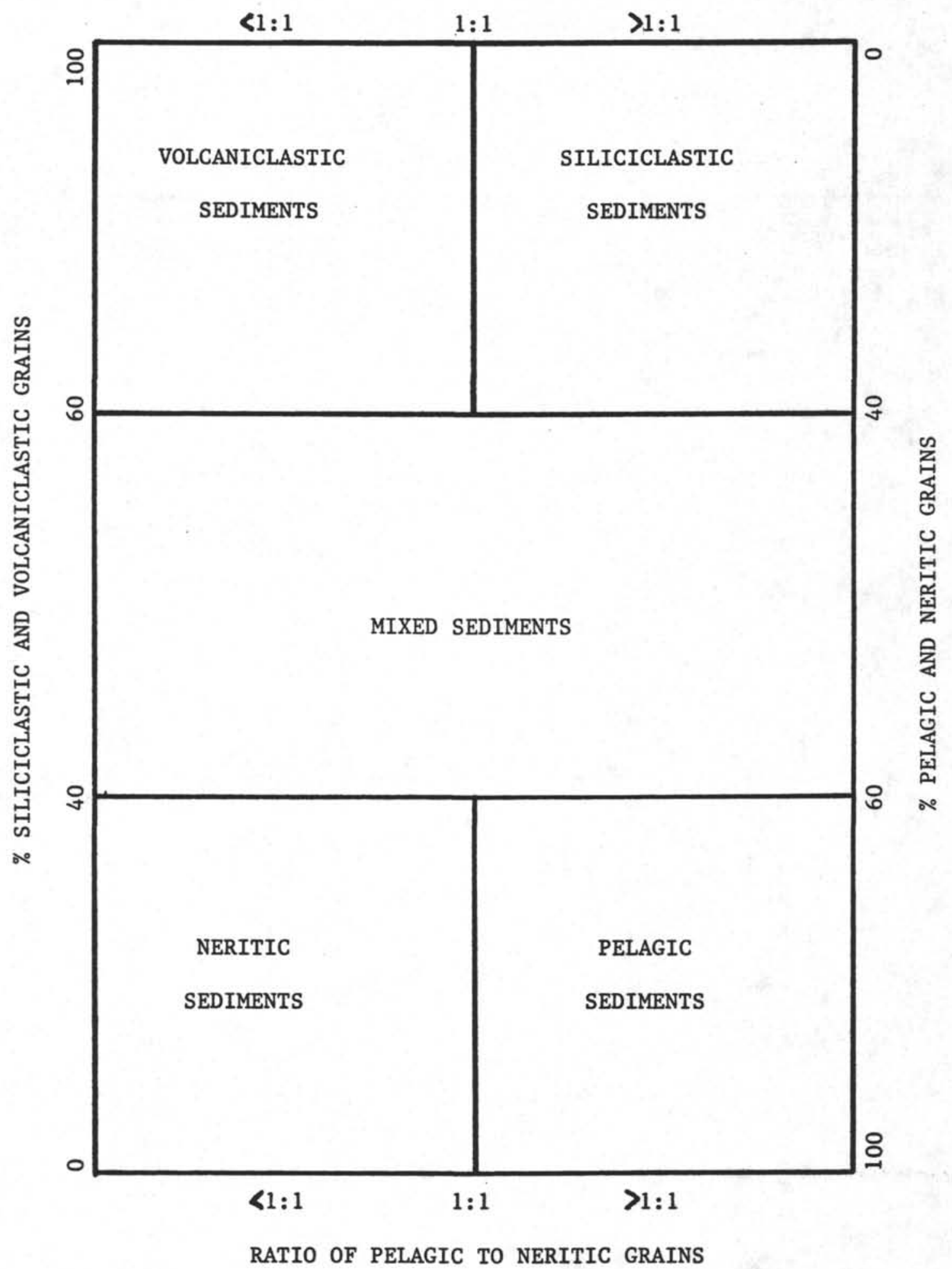

Figure 1. Diagram showing classes of granular sediments. 
Lastly, mixed sediments are composed of 40 to $60 \%$ siliciclastic and volcaniclastic grains, and 40 to $60 \%$ pelagic and neritic grains (Appendix, Example 23).

\section{Classification of Granular Sediment}

A granular sediment can be classified by designating a principal name and najor and minor nodifiers. The principal name of a granular sediment defines its granular-sediment class; the major and ninor modifiers describe the texture, composition, fabric and/or roundness of the grains themselves (Table 1).

Principal Names

Each granular-sediment class has a unique set of principal names:

For pelagic sediment...the principal name describes the composition and degree of consolidation using the following terms (Appendix, Exs. 1-9):

1. ooze: unconsolidated calcareous and/or siliceous pelagic sediments

2. chalk: firm pelagic sediment composed predominantly of calcareous pelagic grains

3. limestone: hard pelagic sediment composed predominantly of calcareous pelagic grains

4. radiolarite, diatomite, and spiculite: firm pelagic sediment composed predominantly of siliceous radiolarians, diatoms, and sponge spicules, respectively, and

5. chert: hard pelagic sediment composed predominantly of siliceous pelagic grains

For neritic sediment...the principal name describes the texture and fabric, using the following terms (from Dunham, 1962; Appendix, Exs. 10-13):

1. boundstone: components organically bound during deposition

2. grainstone: grain-supported fabric, no mud, grains $<2 \mathrm{~mm}$ in size

3. packstone: grain-supported fabric, with intergranular mud, grains < $2 \mathrm{~mm}$ in size

4. wackestone: mud-supported fabric, with greater than $10 \%$ grains, grains $<2 \mathrm{~mm}$ in size

5. mudstone: mud-supported fabric, with 1 ess than $10 \%$ grains

6. floatstone: matrix-supported fabric, grains $>2 \mathrm{~mm}$ in size

7. rudstone: grain-supported fabric, grains $>2 \mathrm{~mm}$ in size

For siliciclastic sediment...the principal name describes the texture, and is assigned according to the following guidelines (Appendix, Exs. 14-19): 1. The Udden-Wentworth grain-size scale (Wentworth, 1922; Table 2) defines the grain-size ranges and the names of the textural groups (gravel, sand, silt and clay) and sub-groups (fine sand, coarse silt, etc.) that are used as the principal names of siliciclastic sediment.

2. When two or more textural groups or sub-groups are present in a siliciclastic sediment, they are listed as principal names in order of increasing abundance (Shepard, 1954; Figure 2).

3. The suffix -stone can be affixed to the principal names sand, silt, and clay when the sediment is lithified; shale can be used as a principal name for a lithified and fissile siltstone or claystone; and conglomerate and breccia are used as principal names of gravels with well-rounded and angular clasts, respectively. 
TABLE 1

OUTLINE OF GRANULAR-SEDIMENT CLASSIFICATION SCHEME

\begin{tabular}{|c|c|c|c|c|}
\hline \multicolumn{2}{|c|}{$\begin{array}{l}\text { SEDIMENT } \\
\text { CLASS }\end{array}$} & $\begin{array}{c}\text { MAJOR } \\
\text { MODIFIERS }\end{array}$ & $\begin{array}{l}\text { PRINCIPAL } \\
\text { NAMES }\end{array}$ & $\begin{array}{c}\text { MINOR } \\
\text { MODIFIERS }\end{array}$ \\
\hline $\begin{array}{l}\text { P } \\
\text { E } \\
\text { L } \\
\text { A } \\
\text { G } \\
\text { I } \\
\text { C }\end{array}$ & $\begin{array}{l}\text { S } \\
\text { E } \\
\text { D } \\
\text { I } \\
\text { M } \\
\text { E } \\
\text { N } \\
\text { T }\end{array}$ & $\begin{array}{l}\text { 1. composition of } \\
\text { pelagic and neritic } \\
\text { grains present in } \\
\text { major amounts } \\
\text { 2. texture of clastic } \\
\text { grains present in } \\
\text { major amounts }\end{array}$ & $\begin{array}{l}\text { 1. ooze } \\
\text { 2. chalk } \\
\text { 3. limestone } \\
\text { 4. radiolarite } \\
\text { 5. diatomite } \\
\text { 6. spiculite } \\
\text { 7. chert }\end{array}$ & $\begin{array}{l}\text { 1. composition of } \\
\text { pelagic and neritic } \\
\text { grains present in } \\
\text { minor amounts } \\
\text { 2. texture of clastic } \\
\text { grains present in } \\
\text { minor amounts }\end{array}$ \\
\hline $\begin{array}{l}\mathrm{N} \\
\mathrm{E} \\
\mathrm{R} \\
\mathrm{I} \\
\mathrm{T} \\
\mathrm{I} \\
\mathrm{C}\end{array}$ & $\begin{array}{l}\text { S } \\
\text { E } \\
\text { D } \\
\text { I } \\
\text { M } \\
\text { E } \\
\text { N }\end{array}$ & $\begin{array}{l}\text { 1. composition of } \\
\text { neritic and pelagic } \\
\text { grains present in } \\
\text { major amounts } \\
\text { 2. texture of clastic } \\
\text { grains present in } \\
\text { major amounts }\end{array}$ & $\begin{array}{l}\text { 1. boundstone } \\
\text { 2. grainstone } \\
\text { 3. packstone } \\
\text { 4. wackestone } \\
\text { 5. mudstone } \\
\text { 6. floatstone } \\
\text { 7. rudstone }\end{array}$ & $\begin{array}{l}\text { 1. composition of } \\
\text { neritic and pelagic } \\
\text { grains present in } \\
\text { minor amounts } \\
\text { 2. texture of clastic } \\
\text { grains present in } \\
\text { minor amounts }\end{array}$ \\
\hline
\end{tabular}

\begin{tabular}{|c|c|c|c|}
\hline $\begin{array}{l}\text { SILICI- } \\
\text { CLASTIC } \\
\text { SEDIMENT }\end{array}$ & $\begin{array}{l}\text { 1. composition of all } \\
\text { grains present in } \\
\text { major amounts } \\
\text { 2. grain fabric } \\
\text { (gravels only) } \\
\text { 3. grain shape } \\
\text { (optional) } \\
\text { 4. sediment color } \\
\text { (optional) }\end{array}$ & $\begin{array}{l}\text { 1. gravel } \\
\text { 2. sand } \\
\text { 3. silt } \\
\text { 4. clay } \\
\text { (etc.) }\end{array}$ & $\begin{array}{l}\text { 1. composition of all } \\
\text { grains present in } \\
\text { minor amounts } \\
\text { 2. texture and compo- } \\
\text { sition of silici- } \\
\text { clastic grains } \\
\text { present as matrix } \\
\text { (for coarse-grained } \\
\text { clastic sediments) }\end{array}$ \\
\hline $\begin{array}{l}\text { VOLCANI- } \\
\text { CLASTIC } \\
\text { SEDIMENT }\end{array}$ & $\begin{array}{l}\text { 1. composition of all } \\
\text { volcaniclasts present } \\
\text { in major amounts } \\
\text { 2. composition of all } \\
\text { pelagic and neritic } \\
\text { grains present in } \\
\text { major amounts } \\
\text { 3. texture of silici- } \\
\text { clastic grains } \\
\text { present in major } \\
\text { amounts }\end{array}$ & $\begin{array}{l}\text { 1. breccia } \\
\text { 2. lapilli } \\
\text { 3. ash/tuff }\end{array}$ & $\begin{array}{l}\text { 1. composition of all } \\
\text { volcaniclasts present } \\
\text { in minor amounts } \\
\text { 2. composition of all } \\
\text { neritic and pelagic } \\
\text { grains present in } \\
\text { minor amounts } \\
\text { 3. texture of silici- } \\
\text { clastic grains } \\
\text { present in minor } \\
\text { amounts }\end{array}$ \\
\hline $\begin{array}{l}\text { MIXED } \\
\text { SEDIMENTS }\end{array}$ & $\begin{array}{l}\text { 1. composition of } \\
\text { neritic and pelagic } \\
\text { grains present in } \\
\text { major amounts } \\
\text { 2. texture of clastic } \\
\text { grains present in } \\
\text { major amounts }\end{array}$ & $\begin{array}{l}\text { 1. mixed } \\
\text { sediments }\end{array}$ & $\begin{array}{l}\text { 1. composition of } \\
\text { neritic and pelagic } \\
\text { grains present in } \\
\text { minor amounts } \\
\text { 2. texture of clastic } \\
\text { grains present in } \\
\text { minor amounts }\end{array}$ \\
\hline
\end{tabular}




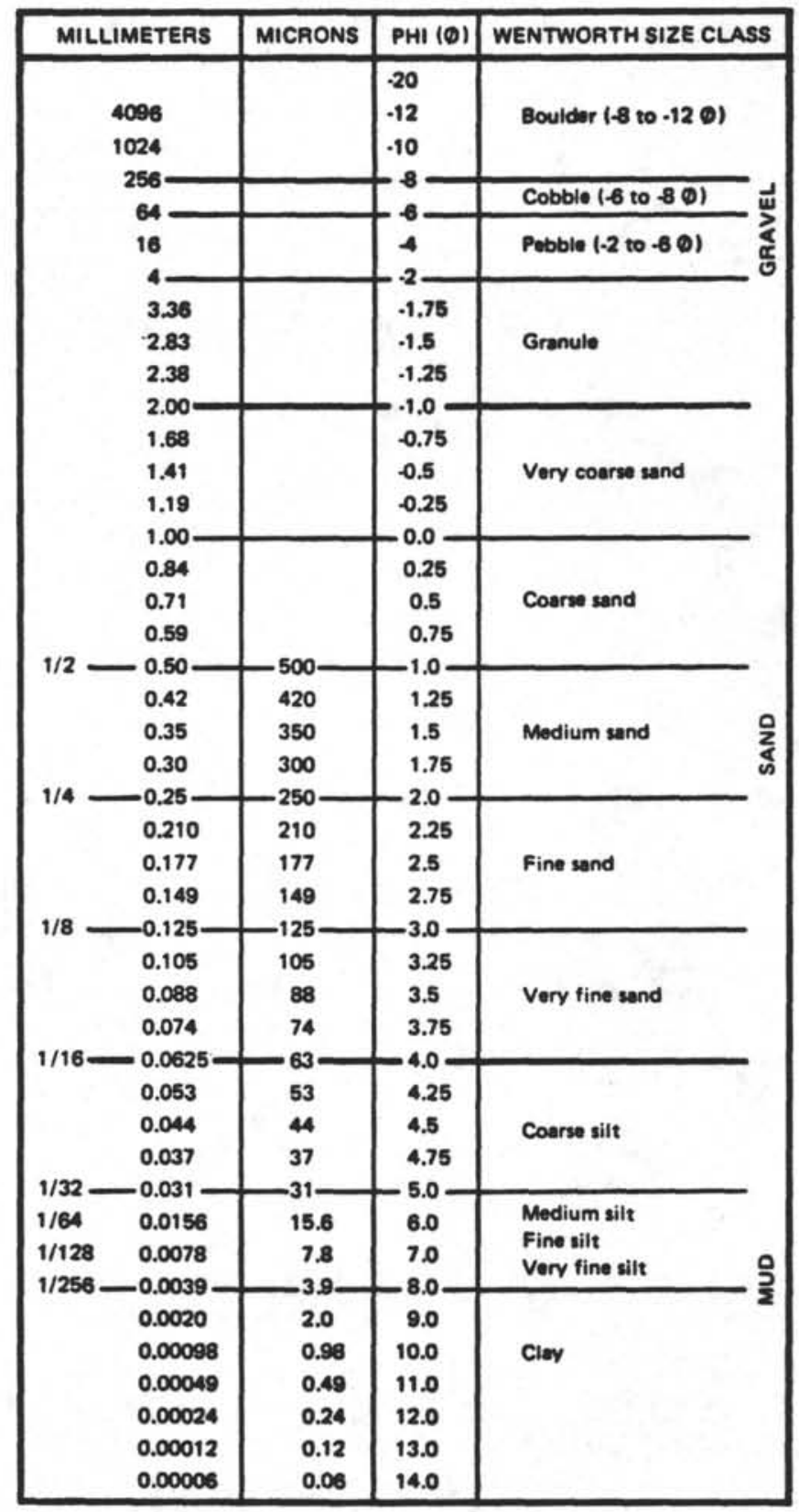

Table 2. Udden-Wentworth grain-size scale for siliciclastic sediments (Wentworth, 1922). 


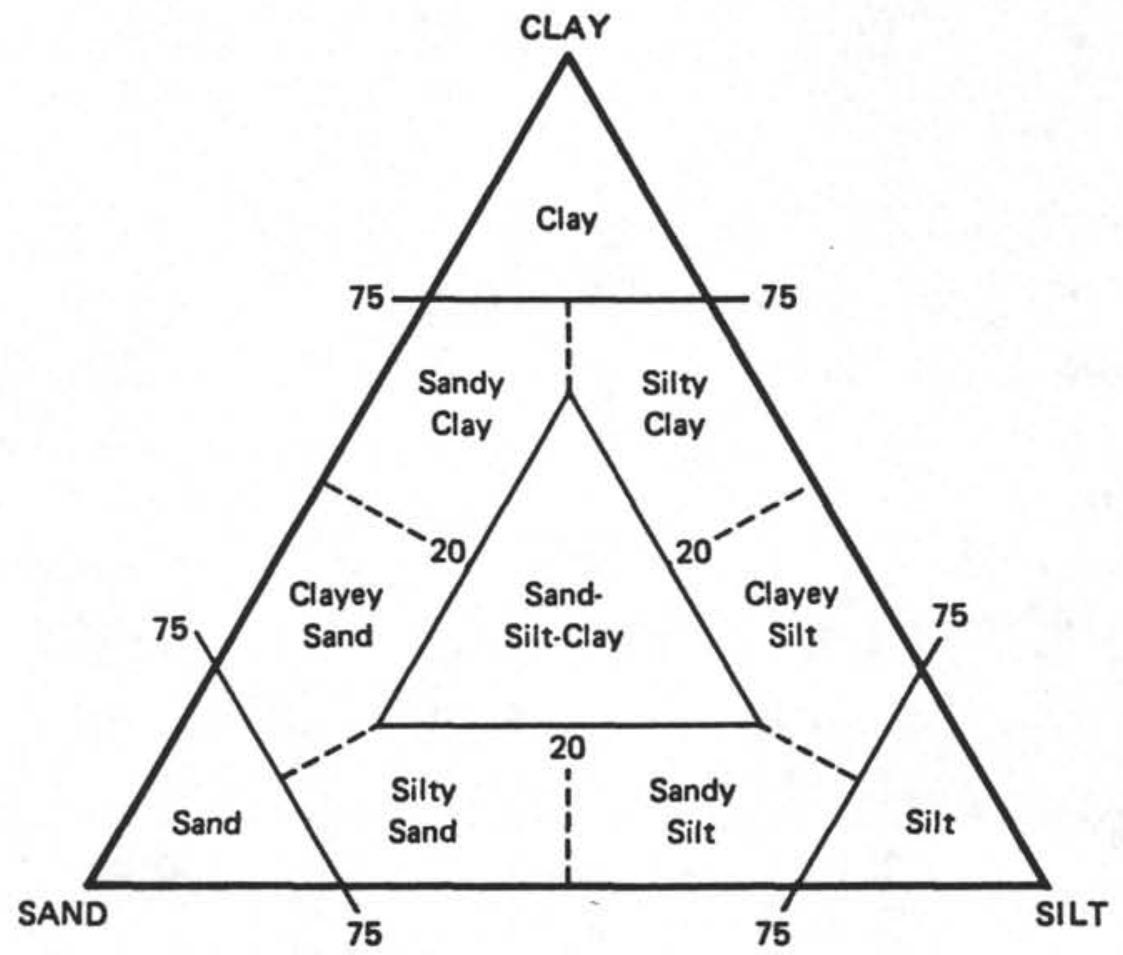

Figure 2. Ternary diagram showing principal names for siliciclastic sediments (from Shepard, 1954). 
4. The terms mud and mudstone should not be used to describe mixtures of silt and clay. The distinction between silt and clay-sized particles is an important part of determining their transport history (e.g., Dean et al., 1985 , p. 251), and thus the relative proportions of these two textural groups should be estimated as well as possible.

For volcaniclastic sediment...the principal name describes the texture. The names and ranges of three textural groups (from Fisher and Schmincke, 1984) are as follows:

1. volcanic breceia: pyroclasts greater than $64 \mathrm{~mm}$ in diameter

2. volcanic lapil11: pyroclasts between 2 and $64 \mathrm{~mm}$ in diameter

3. volcanic ash: pyroclasts less than $2 \mathrm{~mm}$ in diameter. When lithified, use the name tuff.

(Appendix, Examples 20-22)

For mixed sediment...the principal name describes the degree of consolidation, using the terms mixed sediments or mixed sedimentary rocks (Appendix, Example 23).

Major and Minor Modifiers

The principal name of a granular-sediment class is preceded by major modifiers and followed by minor modiflers (preceded by the suffix with) that describe the lithology of the granular sediment in greater detail (Table 1).

The most common uses of major and minor modifiers are to describe the composition and textures of grain types that are present in major (greater than 25\%) and minor (10-25\%) proportions. In addition, major modifiers can be used to describe grain fabric, grain shape, and sediment color. The nomenclature for the major and minor modifiers is outlined as follows:

The composition of pelagic grains can be described with the major and minor modifiers diatom(-aceous), radiolarian, spicules(-ar), siliceous, nannofossil, foraminifer $(-a 1)$, and calcareous. The terms siliceous and calcareous are used generally to describe sediments that are composed of siliceous or calcareous pelagic grains of uncertain origins.

The composition of neritic grains can be described with the following major and minor modifiers:

1. ooid (or oolite): spherical or elliptical non-skeletal particles smaller than $2 \mathrm{~mm}$ in diameter, having a central nucleus surrounded by a rim with concentric or radial fabric;

2. bioclast (or bio): fragment of skeletal remains. Specific names such as nollusean or algal can also be used;

3. pellet (-al): fecal particles from deposit-feeding organisms;

4. Intraclast: reworked carbonate-rock fragment or rip-up clast;

5. pisolite: spherical or elliposidal non-skeletal particle, commonly greater than $2 \mathrm{~mm}$ in diameter, with or without a central nucleus but displaying multiple concentric layers of carbonate;

6. peloid (pel): micritized carbonate particle of unknown origin; and 
7. calcareous, dolonitic, aragonitic, sideritic: these modifiers should be used to describe the composition of carbonate muds or mudstones (micrite) of non-pelagic origins.

The texture of siliciclastic grains is described by the major and minor modifiers gravel, sand, silt, and clay.

The composition of siliciclastic grains can be described by:

1. mineralogy: using modifiers such as quartz, feldspar, glauconite, mica, kaolinite, zeolitic, lithic (for rock fragments), calcareous, gypsiferous, or sapropelic (for detrital clasts of calcium carbonate, gypsum, and organic matter, respectively); and

2. provenance: the source of rock fragments (particularly in gravels, conglomerates, and breccias) can be described by modifiers such as volcanic, sed-1ithic, meta-1ithic, gneissic, basaltic, etc.

The composition of volcaniclastic grains is described by the major and minor modifiers 1ithic (rock fragments), vitric (glass and pumice), and crystal (mineral crystals), or by modifiers that describe the compositions of the liths and crystals (e.g., feldspar or basaltic).

The fabric of the sediment can be described by the major modifiers grain-supported, natrix-supported, and imbricated. Generally, fabric descriptors are applied only to gravels, conglomerates, and breccias, for they provide useful information on their transport history. However, they must be used with extreme caution, for drilling and fluid-flow through a core barrel will often alter the sediment fabric.

The shapes of grains can be visually estimated with a comparitor (Figure 3 ) and described by the major modifiers rounded, sub-rounded, sub-angular, and angular. Generally, shape descriptors are applied only to sand, for they provide useful information on their transport history, and are used at the scientists' discretion.

The color of sediment can be determined with a standard colorcomparitor, such as the Munsell Chart, and is employed as a major modifier. Generally, color descriptors are applied only to silt, clay, and shale, for they provide useful information on their depositional environment or organic content, and are also used at the scientists' discretion.

Steps in Using the Granular-Sediment Classification

The first step in the use of the granular-sediment classification scheme is to estimate the relative proportions of pelagic, neritic, siliciclastic, and volcaniclastic grains within a sample. This can be achieved by a variety of methods, most usually by visual examination of smear slides or thin sections, but also aided by "carbonate-bomb" analysis, $\mathrm{X}$-ray diffractometry, SEM imagery, and other avallable techniques. The relative proportions of the four grain-types should total $100 \%$, but may total to less than $100 \%$ if non-granular components (e.g., cements) have also been estimated. In the latter case, the relative proportions of the three grain-types should be normalized to $100 \%$. 


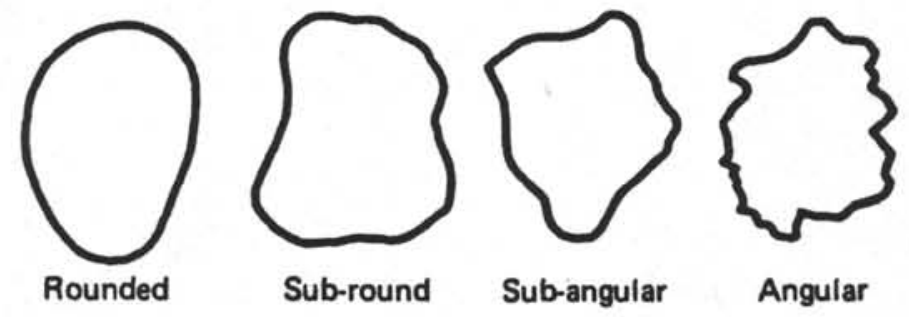

Figure 3. Grain-shape comparitor. 
The second step is to plot the relative proportions of pelagic, neritic, siliciclastic, and volcaniclastic grains on the diagram shown in Figure 1, and thereby determine the granular-sediment class of the sample and its appropriate principal name.

The third step is to attach major and minor modifiers before and after the principal name to describe the 1ithology of the sample in greater detail. Generally, different sets of major and minor modifiers are used for the five sediment classes, according to the following guidelines (Table 1):

For pelagic and neritic sediment, major and minor modifiers that describe the composition of pelagic and neritic grains are 1isted in order of increasing abundance. In addition, the texture (but not the composition) of associated clastic grains are also listed in order of increasing abundance (Appendix, Examples 1-13).

For siliciclastic and volcaniclastic sediment, major and minor modifiers that describe the composition of siliciclastic or volcaniclastic grains are listed in order of increasing abundance. In addition, the composition of associated neritic and pelagic grains are also listed in order of increasing abundance. Lastly, major modifiers that describe grain fabric, grain shape, and sediment color can also be listed before the compositional modifiers. Grain-fabric modifiers are commonly listed for gravels, while grain-shape modifiers are commonly listed for gravels and sand. Sediment-color modifiers are commonly listed for silt and clay (Appendix, Examples 14-22).

For mixed sediment, major and minor modifiers that describe the composition of neritic and pelagic grains and the texture (but not the composition) of clastic grains are listed in order of increasing abundance (Appendix, Example 23).

Examples and Comparison with other Classification Schemes

Examples of the classification of granular sediments with this proposed scheme are shown in the Appendix. In this appendix, each sample is classified by means of the proposed classification scheme, the JOIDES classification scheme, and the classification scheme recently proposed by Dean et al. (1985) for deep-sea sediments.

The proposed classification is very similar to the JOIDES classification scheme, for (1) we classify the sediment with a principal name to describe its class and modifiers (qualifiers) to describe their petrographic characteristics in greater detail, (2) we employ the same terms for principal names and modifiers (for pelagic and clastic sediments) that were used in the JOIDES scheme, and (3) we also 1 ist the major and minor modifiers in order of increasing abundance.

Our sediment classification scheme differs from the JOIDES scheme in three minor ways. First, we distinguish major from minor modifiers, and place the former before the principal name and the latter after the principal name, while the JOIDES classification scheme places all modifiers (qualifiers) regardless of their proportions before the principal name in order of increasing abundance. Second, we do not allow the use of genetic 
terms such as pelagic clay, for our sediment classification is descriptive in nature. Third, we allow for the description of other characteristics of granular sediments, in particular grain shape, grain fabric, and sediment color.

The classification scheme proposed here is also very similar to the sediment classification scheme for deep-sea sediment proposed by Dean et al. (1985), for we use a principal name to describe the sediment class and major and minor modifiers to describe their petrographic characteristics. We differ from Dean et al. (1985) in one minor regard, the location relative to the principal name of the minor modifiers--we place them after the principal name (with the prefix with), but Dean et al. (1985) places them before the principal name (with the suffix -bearing).

Our sediment classification scheme does differ from both the JOIDES and the Dean classification scheme in one major way: the classification of neritic sediments. Neither the JOIDES nor the Dean classification scheme includes a formal classification scheme for coarse-grained carbonates. This has often led to confusion and disagreement among shipboard parties as they sought to improvise such a classification scheme when coarse-grained carbonate rocks were encountered, and resulted in variations in sediment classification between legs.

\section{CLASSIFICATION OF CHEMICAL SEDIMENTS}

Chemical sediment is composed of minerals that formed by inorganic processes such as precipitation from solution or colloidal suspension, deposition of insoluble precipitates, or recrystallization of detrital evaporites and siliceous, calcareous, or carbonaceous (plant) biogenic debris, and generally has a crystalline (1.e., non-granular) texture.

There are five classes of chemical sediments: carbonaceous sediments, evaporites, silicates, carbonates, and metalliferous sediments. Each class of chemical sediment has its own distinctive classification scheme.

\section{Carbonaceous Sediments}

Carbonaceous sedinents are composed of greater than $50 \%$ organic remains, principally plant and algal remains, that has been altered by carbonization, bituminization, or putrification from its original form. The two most common varieties of carbonaceous sediments are the coal series and sapropels.

The coal series is classified according to rank. Four ranks are recognized and used as principal names:

1. peat: soft, earthy organic debris with recognizable plant fragments;

2. brown coal: few recognizable plant fragments, but coal is soft, dull and brown;

3. bituninous coal: black and hard, with bright layers, and breaks into cuboidal fragments, along cleats; and

4. anthracite coal: bright and lustrous, with conchoidal fractures.

Sapropel is a jelly-like ooze or sludge which is principally composed of algal remains and which accumulates in anaerobic environments; its 
lithified equivalent is sapropelitic coal. There is no formal classification for sapropels and sapropelitic coal in this classification scheme.

The principal name of the coal series and sapropels can be modified by terms that describe non-carbonaceous components such as clastic detritus (e.g., muddy peat, clayey sapropel).

OIl shales, asphalt sands, and tar sands are best classified as clastic sediments, for the o1l, asphalt, and tar are cements (albeit poor ones).

\section{Evaporites}

Evaporites are composed of minerals produced from a saline solution that became concentrated by evaporation of the solvent. The evaporites are classified according to their mineralogy using terms such as halite, gypsum, and anhydrite. They may be modified by terms that describe their structure or fabric, such as massive, nodular, nodular-mosaic and chicken-wire.

\section{Silicates/Carbonates}

Silicates and carbonates are defined as sedimentary rocks that are non-granular and non-biogenic in appearance and composed of silicates and carbonate minerals. Silicates and carbonate may have formed from the recrystallization of siliceous and calcareous grains, but are distinguished by the absence of clearly identifiable granular and biogenic components. They may also form as primary precipitates, as in the case of dolomite or proto-dolomite, or as hydrothermal alteration products, such as in the case of zeolites. They are classiffed according to their mineralogy, using principal names such as chert (microcrystalline quartz) or porcellanite (a softer, less dense varlety of chert), calcite, and dolomite. They should also be modified with terms which describe their crystalline (as opposed to granular) nature, such as crystalline, microcrystalline, massive, and anorphous.

Metalliferous Sediments

Netalliferous sediments are a broad category of non-granular non-biogenic sedimentary rocks that includes pyrite, goethite, manganese, chamosite, glauconite, and other metal-bearing minerals. They are classified according to their mineralogy. 


\section{REFERENCES}

Dean, W. E., Leinen, M. and Stow, D.A.V., 1985. Classification of deep-sea fine-grained sediments. Jour. Sed. Petrology, 55(2):250-256.

Dunham, R., 1962. Classification of carbonate rocks according to depositional texture. In Ham, W.E. (Ed.), Classification of Carbonate Rocks. Tulsa, Amer. Assoc. Petrol. Geol., 108-121.

Fisher, R. V., and Schmincke, H.-U., 1984. Pyroclastic rocks. Berlin (Springer-Verlag), 472 p.

Ross, D. A., Neprochnov, Y. P., and Supko, P. R., 1978. Introduction and explanatory notes, Leg 42B, Deep Sea Drilling Project. In Ross, D. A., Neprochnov, Y. P., et al., Init. Repts. DSDP, 42(2): Washington (U.S. Govt Printing Office), 3-15.

Shepard, F., 1954. Nomenclature based on sand-silt-clay ratios. Jour. Sed. Petrology, 24:151-158.

Wentworth, C.K., 1922. A scale of grade and class terms for clastic sediments. Jour. Geology, 30:377-392. 


\section{EXAMPLES OF GRANULAR-SEDIMENT CLASSIFICATION}

PELAGIC SEDIMENTS

Example 1. Firm, fine-grained sediment composed of $100 \%$ nannofossils.

Proposed classification: nannofossil chalk JOIDES classification: nannofossil chalk Dean et al. (1985) classification: nannofossil chalk

Example 2. Firm, fine-grained sediment composed of $100 \%$ diatoms.

Proposed classification: diatomite JOIDES classification: diatonite Dean et al. (1985) classification: diatomite

Example 3. Soft, fine-grained sediment composed of $60 \%$ nannofossils and $40 \%$ diatoms.

Proposed classification: diatom nannofossil ooze JOIDES classification: diaton nannofossil ooze

Dean et al. (1985) classification: diaton nannofossil ooze

Note that the composition of the pelagic grains are 1isted in order of increasing abundance.

Example 4. Firm, fine-grained sediment composed of $30 \%$ diatoms, $50 \%$ radiolarians, and $20 \%$ mollusc shells.

Proposed classification: diatom radiolarite w/bioclasts JOIDES classification: bioclast diatom radiolarite

Dean et al. (1985) classification: bioclast-bearing diatom radiolarite

Note that bioclasts are not clearly distinguished as a minor component in the JOIDES classification.

Example 5. Hard, fine-grained sediment composed of $60 \%$ forams, $5 \%$ diatoms, and $35 \%$ quartz-silt.

Proposed classification: silty foran limestone JOIDES classification: silty foran limestone Dean et al. (1985) classification: silty foral limestone

Note that diatoms, present in proportions of $5 \%$, are not noted in the proposed classification. Also, note that the texture but not the composition of the clastic grains is noted. 
Example 6. Soft, fine-grained sediment composed of $100 \%$ unspecified carbonate grains.

Proposed classification: calcareous ooze JOIDES classification: calcareous ooze

Dean et al. (1985) classification: calcareous ooze

Example 7. Soft, fine-grained sediment composed of $95 \%$ unspecified siliceous grains and $5 \%$ diatoms.

Proposed classification: silfceous ooze JOIDES classification: siliceous ooze Dean et al. (1985) classification: siliceous ooze

Example 8. Firm, fine-grained sediment composed of $65 \%$ forams, $20 \%$ ash, and $15 \%$ radiolarians.

Proposed classification: foran chalk w/radiolarians and ash JOIDES classification: ashy radiolarian foram chalk

Dean et al. (1985) classification: rad-bearing, ash-bearing foran chalk

Note that ash and radiolarians are not clearly distinguished as minor components in the JOIDES classification.

Example 9. Hard, fine-grained sediment composed of $65 \%$ diatoms and $35 \%$ clay.

Proposed classification: clayey diatom chert JOIDES classification: clayey diatom chert

Dean et al. (1985) classification: clayey diatom chert

NERITIC SEDIMENTS

Example 10. Grain-supported carbonate rock with intergranular mud; grains are composed of $60 \%$ ooids and $40 \%$ bioclasts.

Proposed classification: bioclast ooid packstone JOIDES classification: no formal classification Dean et al. (1985) classification: no formal classification

Example 11. Matrix-supported carbonate rock with $30 \%$ intraclasts. Proposed classification: intraclast wackestone JOIDES classification: no formal classification Dean et al. (1985) classification: no formal classification 
Example 12. Grain-supported carbonate rock with no mud; grains are composed of $40 \%$ peloids, $30 \%$ pellets, $20 \%$ bioclasts, and $10 \%$ quartzsand.

Proposed classification: pellet peloid grainstone w/sand and bioclasts

JOIDES classification: no formal classification

Dean et al. (1985) classification: no formal classification

Note that the composition of the sand grains is not noted.

Example 13. Carbonate rock with $60 \%$ micrite (low-Mg calcite), $30 \%$ quartzsilt, and $10 \%$ forams.

Proposed classification: silty calcareous mudstone w/forans JOIDES classification: no formal classification

Dean et al. (1985) classification: no formal classification

\section{SILICICLASTIC SEDIMENTS}

Example 14. Sediment with $100 \%$ sand, composed of well-rounded quartzgrains.

Proposed classification: rounded quartz sand or quartz sand JOIDES classification: quartz sand

Dean et al. (1985) classification: quartz sand

The term rounded is optional to the new classification scheme. Note also that the composition of clastic grains is only used as a modifier in the classification of siliciclastic sediments.

Example 15. Hard sediment with $70 \%$ medium and $30 \%$ fine sandstone, composed of quartz $(60 \%)$, feldspar $(30 \%)$ and mica $(10 \%)$.

Proposed classification: feldspar quartz fine-mediu sandstone w/mica

JOIDES classification: ica feldspar quartz sandstone Dean et al. (1985) classification: aica-bearing feldspar quartz sandstone

Note that mica is not clearly distinguished as a minor component in the JOIDES classification. 
Example 16. Sediment with $80 \%$ gravel composed of gneissic rock fragments, and $20 \%$ intergranular sand composed of quartz.

Proposed classification: grain-supported gneissic gravel w/quartz-sand

JOIDES classification: sandy gneissic gravel

Dean et al. (1985) classification: sand-bearing gneissic gravel

Generally, both the composition and texture of the matrix in coarse-grained siliciclastic sediments are noted.

Example 17. Hard sediment with $50 \%$ clay, $35 \%$ quartz-8ilt, and $15 \%$ forams, red in color.

Proposed classification: red silty claystone w/forans JOIDES classification: foran silty claystone

Dean et al. (1985) classification: foran-bearing silty claystone

Note that the term red is optional to the new classification scheme.

Example 18. Hard sediment with $60 \%$ sand-sized volcanic rock fragments (non-pyroclastic in origin) and $40 \%$ bioclasts.

Proposed classification: bioclast volcanic sandstone JOIDES classification: bioclast volcanic sandstone Dean et al. (1985) classification: bioclast volcanic sandstone

Example 19. Sediment with $60 \%$ quartz-silt and $40 \%$ ash.

Proposed classification: ashy quartz silt JOIDES classification: ashy quartz silt

Dean et al. (1985) classification: ashy quartz silt

\section{VOLCANICLASTIC SEDIMENTS}

Example 20. Sediment with $100 \%$ basaltic rock fragments of volcaniclastic origin and greater than $64 \mathrm{~mm}$ in diameter.

Proposed classification: 1ithic breccia or basaltic breceia JOIDES classification: lithic breccia

Dean et al. (1985) classification: no formal classification 
Example 21. Sediment with $80 \%$ fine-grained volcanic glass and $20 \%$ nannofossils.

Proposed classification: vitric ash w/nannofossils JOIDES classification: nannofossil vitric ash

Dean et al. (1985) classification: nannofossil-bearing vitric ash

Example 22. Sediment with $40 \%$ fine-grained volcanic glass, $35 \%$ sand, and $25 \%$ smectite clay.

Proposed classification: sandy vitric ash w/smectite clay JOIDES classification: clayey sandy vitric ash

Dean et al. (1985) classification: no formal classification

Note that the total proportion of clastic grains is $75 \%$, but that volcaniclastic grains (glass) exceeds

siliciclastic grains (sand) in abundance.

MIXED SEDIMENTS

Example 23. Soft sediment with $45 \%$ nannofossils, $35 \%$ quartz-sand, and $20 \%$ shell debris.

Proposed classification: sandy nannofossil mixed sediment w/bioclasts JOIDES classification: marly nannofossil ooze

Dean et al. (1985) classification: no formal classification

Note that the composition of the sand grains is not noted. 
APPENDIX II: LIST OF REFERENCES PERTINENT TO THE STUDY OF SEDIMENTARY ROCKS THAT ARE AVAILABLE ABOARD SHIP

GC 377 P44 Hsu, Kenneth J., Jenkyns, Hugh C. Pelagic sediments, on land and under the sea: proceedings of a symposium held at the Swiss Federal Institute of Technology, Zurich, 25-6 September 1973. International Assoc. of Sedimentologists European Geophysical Society.

QE 363.B M32 1984

Scope Lab

MacKenzie, W.S. and Guilford, C. Atlas of rock-forming minerals in thin section.

QE 36906

R63 1977

Kerr, P. F. (1st-2nd ed. by Rogers, A. F., and P.F. Kerr). Scope Lab Optical mineralogy.

QE 36906

Shelley, David. Manual of optical mineralogy.

S49 1983

QE 389.61

L 56

Lippmann, Friedrich. Sedimentary carbonate minerals.

QE 389.625 Brindley, G.W. and Brown, G. Crystal structures of clay C79 1980 minerals and their X-ray identification.

QE 433 G7 Griffiths, John Cedric. Scientific method in analysis of sediments.

QE 433 H87 Hutchison, Charles S. Laboratory handbook of petrographic Petrology Lab techniques.

QE 434 W73 Williams, H., Turner, F. J., and Gilbert, C. M. 1982b Petrography: an introduction to the study of rocks in thin sections.

QE 471 A28 Adams, A.E., Mackenzie, W.S., and Guilford, C. Atlas of 1984 sedimentary rocks under the microscope.

QE 471 A73 Scholle, Peter A. and Schulger, Paul R., eds. Aspects of diagenesis: based on symposia (sponsored by the Eastern and by the Rock Mountain Sections, the Society of Economic Paleontologists and Mineralogists).

QE 471 B65 Blatt, H., Middleton, G. V., and Murray, R. C. Origin of 1980 sedimentary rocks.

QE 471 C37 Carver, Robert E. Procedures in sedimentary petrology. 
QE 471

C573 1984

QE 471 L33

1979

(vol. 1 on ship)

QE 471 L46

1984

QE 471065

1979

QE $471 \quad \mathrm{P} 44$

$1964 \mathrm{~b}$

QE 471

P457 1973

QE 471

R425 1980

QE 47115

C3 B37 1981

QE 471.15

CE C1 1983

QE 471.15

C3 C32

1985

QE 471.15

C3 C38 1984

QE 471

C3 C66 1983

QE 471.15

C3 D5 1981

QE 471.15

S36 1983

QE 471.15

D6 D62 1984
McDonald, David A., and Surdam, Ronald C., eds. Clastic diagenesis.

Larsen, Gunnar, and Chilingarian, George V. Diagenesis in sediments and sedimentary rocks.

Lewis, D. W. Practical sedimentology.

American Association of Petroleum Geologists Bulletin. Origin of evaporties: selected papers reprinted from AAPG bulletin.

Pettijohn, F.J., and Potter, P.E. Atlas and glossary of primary sedimentary structures (translations into Spanish, French, and German).

Pettijohn, F.J., Potter, Paul Edwin, and Siever, Raymond. Sand and sandstone.

Reineck, H. -E. and Singh, I.B. Depositional sedimentary environments: with reference to terrigenous clastics.

Bathurst, Robin G.C. Carbonate sediments and their diagenesis.

Harris, Paul M., ed. Carbonate buildups, a core workshop: Dallas, April 16-17, 1983.

Schneidermann, N. and Harris, Paul M. Carbonate cements: based on symposium. Society of Economic Paleontologists and Mineralogists.

Harris, Paul M., ed. Carbonate sands, a core workshop: San Antonio, May 19-20, 1984.

Cook, Harry E., Hine, Albert C., and Mullins, Henry T., Platfrom marg in and deep water carbonates: lecture notes for short course no. 12. Society of Economic Paleontologists and Mineralogists.

Friedman, Gerald M. and Al1, Syed A., comp. Diagenesis of carbonate rocks: cement-porosity relationships: selected papers reprinted from Journal of sedimentary petrology and SEPM special publication no. 13.

Scholle, Peter A. A color 1llustrated guide to carbonate C3 rock constituents, textures, cements and porosities. [Spine title: A color guide to carbonates]

Garrison, R., Kastner, M. and Zenger, D., eds. Dolomites of the Monterey Formation and other organic-rich units. 
QE 471.15

E8 D46 1982

QE 471.15

E8 D4613 1981

\section{Evaporite deposits: 1llustration and interpretation of some environmental sequences.}

QE 471.15

E8 M1 1981

QE 471.15

S25 D5

QE 471.15

S25 D524

QE 471.15

S5 P67

QE 472 A44

QE 472 B67 1979

QE 472 H2 1982

QE 651 W52

QE 720.5

B5 1985

QE 720.5

E5 1984

QE 720.5

I72 1978

QH $212 \mathrm{S3}$

S29 1984

Hanford, C., Robertson, Loucks, R.G., and Davies, Graham R., eds. Depositional and diagenetic spectra of evaporites: a core workshop. Calgary, Canada, June 26-27, 1982.

Chambre syndicale de la recherche et de la production du Dean, Walter Edward, and Schreiber, B. Marine evaporites: lecture notes for short course no. 4.

McBride, Earle F., comp. Diagenesis of sandstone: cement-porosity relationships: selected papers reprinted from the Journal of Sedimentary Petrology.

Ali, Syed A., and Friedman, Gerald M., comps. Diagenesis of sandstones. American Association of Petroleum Geologists.

Potter, P. E., Maynard, J. B., and Pryor, W.A. Sedimentology of shale: study guide and reference source.

Allen, John R. L. Sedimentary structures, their character 1984 and physical basis.

Bouma, A.H. Methods for the study of sedimentary structures.

Harms, J. C., Southard, J. B., and Walker, R. G. Structures and sequences in clastic rocks. Lecture notes for short course no. 9. Society of Economic Paleontologists and Mineralogists.

Wilson, James Lee. Carbonate facies in geologic history.

Curran, H. Allen ed. Blogenic structures: their use in interpreting depositional environments (papers from a symposium at annual SEPM-AAPG meeting, 1980, \& trace fossil session at 26th Int'1 Geological Congress).

Ekdale, A. A., Bromley, R.G. Pemberton, S.G. Ichnology: the use of trace foss1ls in sedimentology and stratigraphy. Soc. Economic Paleontologists and Mineralogists.

Basan, Paul B., ed. (et al.). Trace fossil concepts.

Goldstein, Joseph (et al.). Scanning electron microscopy and X-ray microanalysis: a text for biologists, materials scientists, and geologists. 


\section{APPENDIX III \\ BIBLIOGRAPHY OF THB OCEAN DRTITTIG PROGRAM}

The following technical notes are available from the Ocean Drilling Program, 1000 Discovery Drive, College Station, Texas T7840.

Technical Note \#1 Preliminary time estimates for coring operations (REVISED EDIIION, December 86)

Technical Note *2 Operational and laboratory capabilities of JOIIES RESOLUTION (June 85)

Technical Note *3 Shipboard scientist's handbook (REVISED EDIIION, July 1987)

Technical Note \#4 Five papers on the Dcean Drilling Program from "OCEANS '85' (May 86)

Technical Note $* 5$ Water Chemistry Procedures aboard JOIDES RESOUIIION (September 86)

Technical Note \#6 Organic Geochemistry aboard JOINES RESOLUIION - An Assay (September 86)

Technical Note *7 Shipboard Organic Geochemistry on JOIDES RESOLUIION (September 86)

Technical Note *8 Shipboard Sedimentologists' Handbook' (this document)

Technical Note *9 Deep Sea Drilling Project Data File Documents (Jamuary 88)

Technical Note \#10 A Guide to ODP Tools for Downhole Measurements (June 88) 